Article

\title{
An Exploratory Study of Geospace Perturbations Using Financial Analysis Tools in the Context of Complex Systems
}

\author{
Pavlos I. Zitis ${ }^{1}$, Stelios M. Potirakis ${ }^{1, *(\mathbb{D}) \text {, Georgios Balasis }}{ }^{2, * \mathbb{D}}$ and Konstantinos Eftaxias ${ }^{3}$ \\ 1 Department of Electrical and Electronics Engineering, Ancient Olive Grove Campus, \\ University of West Attica, 250 Thivon and P. Ralli, Aigaleo, GR-12244 Athens, Greece; pzitis@uniwa.gr \\ 2 Institute for Astronomy, Astrophysics, Space Applications and Remote Sensing, \\ National Observatory of Athens, Metaxa and Vasileos Pavlou, Penteli, GR-15236 Athens, Greece \\ 3 Department of Physics, Section of Solid State Physics, University of Athens, Panepistimiopolis, Zografos, \\ GR-15784 Athens, Greece; ceftax@phys.uoa.gr \\ * Correspondence: spoti@uniwa.gr (S.M.P.); gbalasis@noa.gr (G.B.); \\ Tel.: +30-2105381550 (S.M.P.); +30-2108109185 (G.B.)
}

check for updates

Citation: Zitis, P.I.; Potirakis, S.M.; Balasis, G.; Eftaxias, K. An Exploratory Study of Geospace Perturbations Using Financial Analysis Tools in the Context of Complex Systems. Geosciences 2021, 11, 239. https://doi.org/10.3390/ geosciences 11060239

Academic Editors: Simon Wing,

Deodato Tapete and

Jesus Martinez-Frias

Received: 28 February 2021

Accepted: 30 May 2021

Published: 1 June 2021

Publisher's Note: MDPI stays neutral with regard to jurisdictional claims in published maps and institutional affiliations.

Copyright: (C) 2021 by the authors. Licensee MDPI, Basel, Switzerland. This article is an open access article distributed under the terms and conditions of the Creative Commons Attribution (CC BY) license (https:/ / creativecommons.org/licenses/by/ $4.0 /)$.

\begin{abstract}
In the frame of complex systems research, methods used to quantitatively analyze specific dynamic phenomena are often used to analyze phenomena from other disciplines on the grounds that are governed by similar dynamics. Technical analysis is considered the oldest, currently omnipresent, method for financial markets analysis, which uses past prices aiming at the possible short-term forecast of future prices. This work is the first attempt to explore the applicability of technical analysis tools on disturbance storm time $\left(D_{s t}\right)$ index time series, aiming at the identification of similar features between the $D_{s t}$ time series during magnetic storms (MSs) and asset price time series. We employ the following financial analysis tools: simple moving average (SMA), Bollinger bands, and relative strength index $(R S I)$, formulating an analysis approach based on various features, appearing in financial time series during high volatility periods, that could be found during the different phases of the evolution of an MS (onset, main development, and recovery phase), focusing on the temporal sequence they occur. The applicability of the proposed analysis approach is examined on several MS events and the results reveal similar behavior with the financial time series in high volatility periods. We postulate that these specialized data analysis methods could be combined in the future with other statistical and complex systems time series analysis methods in order to form a useful toolbox for the study of geospace perturbations related to natural hazards.
\end{abstract}

Keywords: natural hazards; complex systems; magnetosphere; magnetic storms; $D_{s t}$; technical analysis; Bollinger bands; simple moving average; relative strength index

\section{Introduction}

The relatively new field of complex systems increasingly gains the interest of scientists working on disciplines ranging from physics and engineering to economics, biosciences, and social sciences, e.g., [1-8]. The unique characteristic of complex systems is that they may have certain quantitative features that are intriguingly similar, while their dynamics are governed by a set of universal principles $[9,10]$. Thus, complex systems from different disciplines are often analyzed within similar mathematical frameworks.

There is an apparent paradox in the abovementioned suggestion. How is it possible for a concept as multifaceted as complexity to serve as a unifying direction? When one considers a phenomenon that is "complex", it refers to a system whose phenomenological laws, which describe the global behavior of the system, are not necessarily directly related to the "microscopic" laws that regulate the evolution of its elementary parts [11]. This is a basic reason for our interest in complexity [11-15]. There is a common factor in these seemingly diverse phenomena. The complex systems adopt a pattern of behavior almost completely determined by the collective effects. They exhibit remarkable properties of 
self-organization and emergence of coherent structure over many scales. The main feature of collective behavior is that an individual unit's action is dominated by the influence of its neighbors; the unit behaves differently from the way it would behave on its own, so that, all units simultaneously alter their behavior to a common pattern. Thus, new features emerge as we move from one scale to another, and the science of complexity is about revealing the principles that govern the ways in which new properties appear [11].

Two of the most vivid and richest examples of the dynamics of a complex system at work is that of economic systems (financial markets) [14,16-24] and Earth's magnetosphere [25-35]. Their richness in interactions render them characteristic examples of complex dynamics. In this paper we aim at the identification of similar features between the $D_{s t}$ time series during magnetic storms (MSs) and the stock price time series in high volatility periods. Magnetic storms occur when the accumulated input power from the solar wind to magnetosphere exceeds a certain threshold. Notice, MSs are a main element of space weather: they have severe impacts on both spaceborne and ground-based technological systems [36]. Magnetic storm intensity is usually represented by an average of the geomagnetic perturbations measured at four mid-latitude magnetic observatories, known as the disturbance storm time $\left(D_{s t}\right)$ index [37]. The hourly $D_{s t}$ index is used as a global index for the monitoring of Earth's magnetosphere, which could be either in a quiet (normal) or a stormy (pathological) state. Herein, we focus on the analysis of $D_{s t}$ time series around the occurrence of MSs, pointing out that many features of $D_{s t}$ time series during these periods are similar to those of extreme stock price variations. Moreover, we discuss a possible use of the resulting information in the frame of multidisciplinary efforts for the study of geospace perturbations related to natural hazards.

This work aims at enhancing the suggestion that transferring ideas, methods, and insights from investigations in hitherto disparate areas, namely economic and geophysical systems, will cross-fertilize and lead to important new results concerning the dynamics of the corresponding extreme events, i.e., dynamics of financial crises and MSs. A question effortlessly arising is whether the aforementioned notion is groundless or not. A number of analysis methods have been mutually used to study the dynamics of financial markets, earthquakes, and magnetosphere, e.g., [17,32-35,38-50]. Several authors have suggested that earthquake dynamics and the dynamics of economic (financial) systems can be analyzed within similar mathematical frameworks, e.g., [10] and references therein [14,51-54]. On the other hand, authors have also suggested that earthquake dynamics and MSs dynamics can be analyzed within similar mathematical frameworks, as well, e.g., [33-35]. Thus, the question whether these two complex systems, namely financial crises and MSs, can be analyzed within the same mathematical framework seems to be justified. This conclusion is specifically enhanced by the fact that the signature of discrete scale invariance (DSI) [49] characterizes the earthquakes and financial crises [49], and MS [34], as well. It is important to stress the practical consequence of the presence of the corresponding log-periodic structures. For prediction purposes, it is much more constrained and thus reliable to fit a part of an oscillating data than a simple power law which can be quite general, especially in the presence of noise [49].

Technical analysis, primarily employed for the empirical analysis of financial time series, is considered the oldest method for investment analysis with origins dating perhaps before the 1800s [55]. Charles Dow, who developed the famous Dow Theory, which was later refined by S. A. Nelson, W. P. Hamilton, and R. Rhea in the early 20th century, is considered the pioneer of modern technical analysis [56]. Nowadays, technical analysis is omnipresent in financial markets analysis. Taylor and Allen [57], as well as Menkhoff [58], nearly two decades later, analyzed data of 692 fund managers in five countries, including the USA, concluding that at least $90 \%$ or $87 \%$, respectively, of the involved respondents pay enough attention to technical analysis in order to take investment decisions primarily on short-term investments. Note that technical analysis has also been used in other disciplines too, such as medicine, e.g., [59,60], data communications, e.g., [61,62], textile engineering, e.g., [63], wireless sensor networks, e.g., [64], and photovoltaic systems [65]. 
Technical analysis uses past prices having as target the possible identification of future prices. The efficiency of technical analysis in markets which are characterized by long-term memory, as determined by the Hurst exponent, has been recently studied in fifteen of the largest global equity markets [55].

In this paper, we investigate the use of some widely employed tools of technical analysis for the study of the temporal evolution of $D_{s t}$ time series. Specifically, we study here whether the simple moving average $(S M A)$, the Bollinger bands, and the relative strength index $(R S I)$ can reveal that $D_{s t}$ time series during MSs present behavior similar to the one found when they are applied to financial time series during high volatility periods. Note that, to the best of our knowledge, this is the first time that such a study appears in the literature. Based on the present exploratory study's outcomes, it is discussed the possibility that (i) technical analysis tools could in the future be combined with other time series tools, statistical or complex systems ones (e.g., log-periodic corrections), in order to study the temporal evolution of geomagnetic perturbations related to an MS, and (ii) may offer ideas in order to provide a framework of technical analysis for the study of geospace perturbations related to other natural hazards (e.g., earthquakes, tsunamis, etc.).

The remainder of this contribution is organized as follows: The necessary background information on the used technical analysis tools, as well as information about the analyzed time series, is provided in Section 2. In Section 3 we describe the behavior of the considered technical analysis tools when applied on $D_{s t}$ time series during the evolution of an MS, while an analysis approach for the use of the specific tools in the study of MSs is introduced as a step-by-step procedure. The analysis of different $D_{s t}$ time series including MSs is presented, and the obtained results are discussed in Section 4. Finally, in Section 5, the presented $D_{s t}$ analysis method and obtained results are discussed, while the conclusions are summarized.

\section{Data and Analysis Methods}

In the following, we provide a brief introduction to the main information and equations related to the analysis methods which are used in this paper, as well as a description of the Earth's magnetosphere observables ( $D_{s t}$ time series) on which these methods are applied.

\subsection{Methods}

The main aspects of the simple moving average $(S M A)$, Bollinger bands, and relative strength index (RSI) methods, which are widely used in the empirical analysis of financial time series known as "technical analysis", are briefly presented in the following. The introduction to these methods is presented in terms of the information which is extracted by each one of them during the analysis of stock market time series, while all necessary mathematical formulas for their application are also given.

\subsubsection{Moving Average}

The moving average is one of the most popular and widely used tools of technical analysis. It is characterized as an automated trendline and it is considered an objective and reliable tool for stock market analysis [66,67]. The information provided by moving average is threefold [68]: (i) it determines the direction of the trend, (ii) it confirms the change of the trend, and (iii) it smooths the extraneous data which are often misguiding. As it is expected, the moving average responds to price changes with lag, since it is calculated using past prices. The longer the length of the calculation period, the slower it responds to changes [69]. A wide variety of moving averages are used in stock market time series analysis. In this paper we refer to the simple moving average $(S M A)$ which is defined at any time point $k \geq n$ by the following formula [56]:

$$
S M A_{k}=\frac{1}{n} \sum_{i=k-n+1}^{k} C_{i},
$$


where $S M A_{k}$ is the simple moving average at the (sample) time $k, C_{i}$ is the closing price for the (sample) time $i, n$ is the total number of consecutive samples to be included in the moving mean calculation, and $k$ is the number of the sample being studied within the total number of samples in the database.

The most popular interpretations of the moving average results are the following: (i) upward (or downward) crossing of the moving average curve by the price curve is a sign of upward (or downward) trend [70]; (ii) upward (or downward) slope of moving average curve means upward (or downward) trend of the price; also if the slope is steep, the trend is expected to be strong, while, conversely, if the slope is gentle, the trend is expected to be weak [71]; (iii) the moving average often acts as "support" and "resistance" level of the price trend [72], i.e., if the price values and the moving average are plotted on the same chart, and the chart shows that the price value, within a time period, never seems to be able to rise above a value $A$ or fall below a value $B$ of the moving average, then the resistance level is the value $A$ and the support level is the value $B$, respectively; (iv) the prices have the tendency to return to the value of moving average [72].

\subsubsection{Bollinger Bands}

The Bollinger bands were developed by John Bollinger in the 1980s and are a tool of technical analysis that belongs to a wider category of price analysis methods called "trading bands". The trading bands in general consist of curves lying at a distance above and below a measure of central tendency [73,74]. In the specific case of Bollinger bands, the measure of central tendency is the simple moving average, and the distance of the curves from the moving average depends on the local standard deviation of prices. The standard deviation measures the volatility of prices, since it is a statistical measure that indicates how far prices range from average [75]. Due to the way Bollinger bands are constructed, their distance regulates itself and adapts to the volatility of market prices. When volatility is high, the bands widen, while when it is small, the bands narrow, approaching the moving average [76]. The Bollinger bands consist of three curves: the middle band (MiddleB), the upper band (UpperB), and the lower band (LowerB), calculated by the following formulas, respectively:

$$
\begin{gathered}
\text { MiddleB }=S M A, \\
\text { Upper } B=S M A+K \cdot \sigma_{n}, \\
\text { Lower } B=S M A-K \cdot \sigma_{n},
\end{gathered}
$$

where $n$ is the calculation period of $S M A, \sigma_{n}=\sqrt{\frac{1}{n} \sum_{i=k-n}^{k}\left(x_{i}-S M A\right)^{2}}$ is the standard deviation of the same period, and $K$ is a parameter that determines the distance of the bands from the moving average.

The originally proposed pairs of $n$ and $K$ are [73]: $(n=10, K=1.9),(n=20, K=2)$, and $(n=50, K=2.1)$. As it is expected, these parameters were selected so that the majority of the prices fall within the bands. It has been argued that, in most markets, about $88 \%$ to $89 \%$ of the prices are within the bands for $n=20$ and $K=2$ [73]. This has been further supported by the work of Liu et al. [76] who studied stock market indices (DOW, NASDAQ, and S\&P500) from 1991 to 2005, concluding that $94 \%$ of the daily closing prices were within the Bollinger bands. Moreover, $\mathrm{Xu}$ and Yang [77] reached a similar conclusion after studying the indices SPY, QQQ, and DIA for the period 2008 to 2011, namely during the financial crises of 2008, and found that more than $95 \%$ of the prices lie within Bollinger bands [77].

The most popular interpretations of Bollinger bands results are the following [70]: (i) after the narrowing of the bands, the prices usually have a sharp change; (ii) when prices move outside the bands, this implies that the current trend is going to continue; (iii) when local maximum (or local minimum) which is outside of the bands is followed by local maximum (or local minimum) inside the bands, this is a feature indicating an upcoming reversing of the current trend; (iv) for a price change which starts at one of the bands, it is 
expected that this will continue changing, maintaining its trend, until it covers all the way to the other band.

Finally, we should mention that originally the Bollinger bands method was exclusively used in finance time series analysis, but over time, this method has been proven to find application in various fields such as textile engineering, data networks, wireless sensor network, and photovoltaic systems, e.g., [62-65].

\subsubsection{Relative Strength Index (RSI)}

Relative strength index (RSI) was developed by W. J. Wilder [78]. It is one of the bestknown momentum indicators and measures the speed and the magnitude of the direction of price movements [77,79]. The RSI takes values in the interval; generally, values of RSI over 70 suggest probable "overbought" situation, while values below 30 indicate a probable "oversold" situation. Overbought (or oversold) is a term used to describe the situation following a rise (or decline) in share prices, in which some investors believe that prices have risen (or fallen) exceedingly, i.e., the share is overvalued (or undervalued) relative to fundamentals [80]. The specific threshold values (70 and 30) are not absolute; other threshold values also appear in the literature [72]. The RSI value is calculated using the following equation [78]:

$$
R S I=100-\left[\frac{100}{1+R S}\right],
$$

where $R S=\frac{\text { moving average of } n \text { days closes UP }}{\text { moving average of } n \text { days closes DOWN }}$, the originally suggested calculation period for the moving average is $n=14$ [78]. However, other values for the calculation period, $n$, have also been considered later, with the most popular being: 5, 7, 8, 10, and 20 days [56]. Apparently, the smaller the calculation period, $n$, the more sensitive to price changes is the $R S I$, while in the opposite case the index is less sensitive [56].

The following interpretations of the RSI analysis results have been proposed [78]: (i) the RSI often reaches a zero slope (local maximum) over 70 or a zero slope (local minimum) below 30, prior to a local maximum or local minimum of the prices, respectively, providing a feature indicating a possible trend reversal; (ii) the chart of RSI shows often formations, such as "head" and "shoulders" (when three peaks appear successively and the second is higher than the other two, then the first and third are called shoulders and the second is called head) or "triangles" (a triangle occurs as the range between peaks and troughs narrows), that indicate a possible change of trend, formations sometimes not evident in the price chart; (iii) "failure swings" above the level of 70 (or below the level of 30) are very strong evidence of a trend reversal. The term failure swing describes a local maximum (or local minimum) of the RSI curve above 70 (or below 30) that is followed by a second local maximum (or local minimum) below 70 (or above 30); (iv) the RSI shows several times clearer "resistance" and "support" levels of the chart of prices, i.e., if the RSI value is plotted on a chart, and the chart shows that the RSI value, within a time period, never seems to be able to rise above a value $A$ or fall below a value $B$, then the resistance level is the value A and the support level is the value B [80]; (v) when "divergence" between the prices and the RSI values are observed, namely new high (or low) that is not verified by a new high (or low) of the RSI values, the prices tend to follow the direction of motion of the RSI values.

\subsection{Data}

Magnetic storms are the most prominent global phenomenon of geospace dynamics, interlinking the solar wind, magnetosphere, ionosphere, atmosphere, and, occasionally, the Earth's surface [36,81,82]. Magnetic storms produce a number of distinct physical effects in the near-Earth space environment: acceleration of charged particles in space, intensification of electric currents in space and on the ground, impressive aurora displays, and global magnetic disturbances on the Earth's surface [83]. The latter serve as the basis for storm monitoring via the hourly $D_{s t}$ index, which is computed from an average over four mid-latitude magnetic observatories [37]; $D_{s t}$ is considered a global index for the mon- 
itoring of Earth's magnetosphere. The size of a geomagnetic storm is classified as moderate $\left(-100 \mathrm{nT}<\right.$ minimum of $\left.D_{s t}<-50 \mathrm{nT}\right)$, intense $\left(-250 \mathrm{nT}<\right.$ minimum $\left.D_{s t}<-100 \mathrm{nT}\right)$, or super-storm (minimum of $D_{s t}<-250 \mathrm{nT}$ ).

The here-proposed MS analysis approach was extracted after the analysis of more than 20 MSs of all classes that occurred from 1958 to 2015; their time of occurrence and magnitudes are shown in the second and third column of Table 1, respectively. An illustrative example of application is given in parallel to the presentation of the proposed analysis approach (cf. Section 3) using a super-storm which occurred on 31 March 2001 with peak $D_{s t}$ value of $-387 \mathrm{nT}$ (line no. 13 of Table 1). Moreover, we present in detail (in Section 4) the analysis of four characteristic cases of MSs which occurred on 26 May 1967, 22 October 1999, 08 November 2004, and 25 October 2011 with peak $D_{s t}$ values of $-387 \mathrm{nT}$, $-237 \mathrm{nT},-374 \mathrm{nT}$, and $-147 \mathrm{nT}$, shown in lines no. 8, 10, 18, and 23 of Table 1, respectively. Informative plots summarizing the analysis results for the full set of analyzed MSs listed in Table 1 are provided as online supplementary material. 


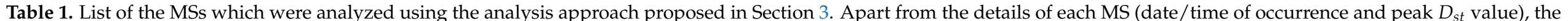

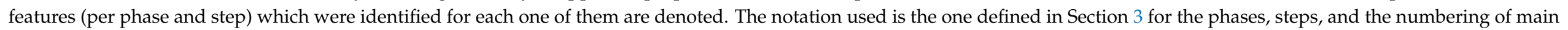

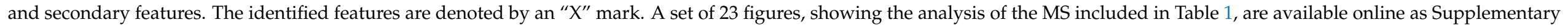
Material.

\begin{tabular}{|c|c|c|c|c|c|c|c|c|c|c|c|c|c|c|c|c|c|c|c|c|c|c|c|c|}
\hline \multirow{3}{*}{$\begin{array}{c}\text { M. } \\
\text { Storm } \\
\#\end{array}$} & \multirow{3}{*}{$\begin{array}{l}\text { Occurrence } \\
\text { Date }\end{array}$} & \multirow{3}{*}{$\begin{array}{c}\text { Peak Dst } \\
\text { (nT) }\end{array}$} & \multicolumn{5}{|c|}{ Phase I } & \multicolumn{7}{|c|}{ Phase II } & \multicolumn{10}{|c|}{ Phase III } \\
\hline & & & \multicolumn{2}{|l|}{$\begin{array}{l}\text { Step } \\
\text { I.a }\end{array}$} & \multicolumn{3}{|c|}{ Step I.b } & \multicolumn{3}{|c|}{ Step II.a } & \multirow{2}{*}{$\begin{array}{c}\begin{array}{c}\text { Step } \\
\text { II.b }\end{array} \\
\text { S.v }\end{array}$} & \multicolumn{2}{|c|}{ Step II.c } & \multirow{2}{*}{$\begin{array}{c}\text { Step } \\
\text { II.d }\end{array}$} & \multicolumn{2}{|c|}{ Step III.a } & \multicolumn{2}{|c|}{ Step III.b } & \multicolumn{5}{|c|}{ Step III.c } & \multirow{2}{*}{$\begin{array}{c}\text { Step } \\
\text { III.d } \\
\text { M.xii }\end{array}$} \\
\hline & & & M.i & S.i & S.ii & S.iii & S.iv & M.ii & M.iii & M.iv & & M.v & M.vi & & M.vii & S.vii & M.viii & M.ix & M.x & M.xi & M.xii & S.viii & S.iii & \\
\hline 1 & $11 / 02 / 1958$ & -426 & $x$ & & & & & $x$ & $x$ & $x$ & $x$ & $x$ & $x$ & & $x$ & $x$ & $x$ & $\mathrm{x}$ & $x$ & $x$ & $x$ & & $x$ & $x$ \\
\hline 2 & $08 / 07 / 1958$ & -330 & $x$ & $x$ & & & & $x$ & $\mathrm{x}$ & $\mathrm{x}$ & $x$ & $\mathrm{x}$ & $x$ & $x$ & $\mathrm{x}$ & $x$ & $\mathrm{x}$ & $x$ & $\mathrm{x}$ & $x$ & $\mathrm{x}$ & $x$ & & $x$ \\
\hline 3 & $23 / 04 / 1959$ & -128 & $\mathrm{x}$ & $x$ & & & & $\mathrm{x}$ & $\mathrm{x}$ & $\mathrm{x}$ & $\mathrm{x}$ & $\mathrm{x}$ & $\mathrm{x}$ & & $\mathrm{x}$ & $\mathrm{x}$ & $\mathrm{x}$ & $\mathrm{x}$ & $\mathrm{x}$ & $\mathrm{x}$ & $\mathrm{x}$ & & $x$ & $\mathrm{x}$ \\
\hline 4 & $15 / 07 / 1959$ & -429 & $x$ & $x$ & & & & $\mathrm{x}$ & $x$ & $\mathrm{x}$ & $x$ & $x$ & $\mathrm{x}$ & $x$ & $\mathrm{x}$ & $x$ & $\mathrm{x}$ & $x$ & $x$ & $\mathrm{x}$ & $x$ & & & $\mathrm{x}$ \\
\hline 5 & $28 / 10 / 1961$ & -272 & $\mathrm{x}$ & $\mathrm{x}$ & & & & $\mathrm{x}$ & $\mathrm{x}$ & $\mathrm{x}$ & $\mathrm{x}$ & $\mathrm{x}$ & $\mathrm{x}$ & $\mathrm{x}$ & $\mathrm{x}$ & $\mathrm{x}$ & $\mathrm{x}$ & $\mathrm{x}$ & $\mathrm{x}$ & $\mathrm{x}$ & $\mathrm{x}$ & $x$ & $x$ & $\mathrm{x}$ \\
\hline 6 & $16 / 02 / 1962$ & -78 & $\mathrm{x}$ & & $\mathrm{x}$ & & $x$ & $x$ & $\mathrm{x}$ & $x$ & & $\mathrm{x}$ & $x$ & $\mathrm{x}$ & $\mathrm{x}$ & & $\mathrm{x}$ & $\mathrm{x}$ & $\mathrm{x}$ & $x$ & $\mathrm{x}$ & & & $\mathrm{x}$ \\
\hline 7 & $10 / 02 / 1963$ & -62 & $\mathrm{x}$ & $x$ & $\mathrm{x}$ & & & $\mathrm{x}$ & $\mathrm{x}$ & $x$ & $\mathrm{x}$ & $\mathrm{x}$ & $x$ & & $\mathrm{x}$ & $\mathrm{x}$ & $\mathrm{x}$ & $\mathrm{x}$ & $\mathrm{x}$ & $x$ & $\mathrm{x}$ & & & $\mathrm{x}$ \\
\hline 9 & 09/11/1991 & -354 & $\mathrm{x}$ & $x$ & & & & $x$ & $x$ & $x$ & $\mathrm{x}$ & $x$ & $x$ & $x$ & $x$ & $x$ & $x$ & $\mathrm{x}$ & $x$ & $\mathrm{x}$ & $x$ & & & $x$ \\
\hline 10 & $22 / 10 / 1999$ & -237 & $\mathrm{x}$ & & & & & $\mathrm{x}$ & $\mathrm{x}$ & $\mathrm{x}$ & $\mathrm{x}$ & $\mathrm{x}$ & $\mathrm{x}$ & $\mathrm{x}$ & $\mathrm{x}$ & $\mathrm{x}$ & $\mathrm{x}$ & $\mathrm{x}$ & $\mathrm{x}$ & $x$ & $\mathrm{x}$ & & $\mathrm{x}$ & $\mathrm{x}$ \\
\hline 11 & $07 / 04 / 2000$ & -288 & $x$ & & $x$ & & & $x$ & $x$ & $x$ & $x$ & $x$ & $x$ & $x$ & $x$ & $x$ & $\mathrm{x}$ & $x$ & $x$ & $x$ & $\mathrm{x}$ & $x$ & & $x$ \\
\hline 12 & $16 / 07 / 2000$ & -301 & $\mathrm{x}$ & $x$ & & & & $\mathrm{x}$ & $\mathrm{x}$ & $\mathrm{x}$ & $\mathrm{x}$ & $\mathrm{x}$ & $\mathrm{x}$ & $\mathrm{x}$ & $\mathrm{x}$ & $\mathrm{x}$ & $\mathrm{x}$ & $\mathrm{x}$ & $\mathrm{x}$ & $\mathrm{x}$ & $\mathrm{x}$ & & $x$ & $\mathrm{x}$ \\
\hline 13 & $31 / 03 / 2001$ & -387 & $\mathrm{x}$ & $\mathrm{X}$ & $x$ & $x$ & $x$ & $\mathrm{x}$ & $\mathrm{x}$ & $\mathrm{x}$ & $\mathrm{x}$ & $\mathrm{x}$ & $\mathrm{x}$ & $\mathrm{x}$ & $\mathrm{x}$ & $\mathrm{x}$ & $\mathrm{x}$ & $\mathrm{x}$ & $\mathrm{x}$ & $\mathrm{x}$ & $\mathrm{x}$ & $\mathrm{x}$ & $\mathrm{x}$ & $\mathrm{x}$ \\
\hline 14 & $12 / 04 / 2001$ & -271 & $\mathrm{x}$ & $\mathrm{x}$ & & & & $\mathrm{x}$ & $\mathrm{x}$ & $\mathrm{x}$ & $\mathrm{x}$ & $\mathrm{x}$ & $x$ & & $\mathrm{x}$ & $\mathrm{x}$ & $\mathrm{x}$ & $\mathrm{x}$ & $\mathrm{x}$ & $\mathrm{x}$ & $\mathrm{x}$ & & & $\mathrm{x}$ \\
\hline 15 & $24 / 11 / 2001$ & -221 & $x$ & $x$ & & & & $x$ & $x$ & $x$ & $x$ & $x$ & $x$ & $x$ & $x$ & $x$ & $x$ & $x$ & $x$ & $x$ & $x$ & & $x$ & $x$ \\
\hline 16 & $20 / 11 / 2003$ & -422 & $\mathrm{x}$ & & & & & $\mathrm{x}$ & $\mathrm{x}$ & $\mathrm{x}$ & $\mathrm{x}$ & $\mathrm{x}$ & $\mathrm{x}$ & $\mathrm{x}$ & $\mathrm{x}$ & $\mathrm{x}$ & $\mathrm{x}$ & $\mathrm{x}$ & $\mathrm{x}$ & $x$ & $\mathrm{x}$ & & & $\mathrm{x}$ \\
\hline 17 & $11 / 02 / 2004$ & -93 & $x$ & & & $x$ & & $x$ & $x$ & $x$ & $x$ & $x$ & $x$ & $x$ & $x$ & $x$ & $x$ & $x$ & $x$ & $x$ & $x$ & & $x$ & $x$ \\
\hline 18 & $08 / 11 / 2004$ & -374 & $\mathrm{x}$ & & $\mathrm{x}$ & $\mathrm{x}$ & & $\mathrm{x}$ & $\mathrm{x}$ & $\mathrm{x}$ & $\mathrm{x}$ & $\mathrm{x}$ & $x$ & $\mathrm{x}$ & $\mathrm{x}$ & $\mathrm{x}$ & $x$ & $\mathrm{x}$ & $\mathrm{x}$ & $\mathrm{x}$ & $\mathrm{x}$ & & $\mathrm{x}$ & $\mathrm{x}$ \\
\hline 19 & $15 / 05 / 2005$ & -247 & $x$ & $x$ & & & & $x$ & $\mathrm{x}$ & $x$ & $x$ & $\mathrm{x}$ & $x$ & $\mathrm{x}$ & $\mathrm{x}$ & $\mathrm{x}$ & $x$ & $\mathrm{x}$ & $\mathrm{x}$ & $x$ & $\mathrm{x}$ & & $\mathrm{x}$ & $\mathrm{x}$ \\
\hline 20 & $24 / 08 / 2005$ & -184 & $\mathrm{x}$ & $\mathrm{x}$ & & & & $x$ & $\mathrm{x}$ & $\mathrm{x}$ & $\mathrm{x}$ & $\mathrm{x}$ & $\mathrm{x}$ & $\mathrm{x}$ & $\mathrm{x}$ & $\mathrm{x}$ & $\mathrm{x}$ & $\mathrm{x}$ & $\mathrm{x}$ & $\mathrm{x}$ & $\mathrm{x}$ & $x$ & & $\mathrm{x}$ \\
\hline 21 & $31 / 08 / 2005$ & -122 & $x$ & & & & & $x$ & $x$ & $x$ & $x$ & $x$ & $x$ & $x$ & $\mathrm{x}$ & $x$ & $x$ & $x$ & $x$ & $x$ & $x$ & & $x$ & $x$ \\
\hline 24 & $17 / 03 / 2015$ & -223 & $x$ & $x$ & & & & $x$ & $x$ & $x$ & & $x$ & $x$ & $x$ & $x$ & & $x$ & $x$ & $x$ & $x$ & $x$ & & & $x$ \\
\hline
\end{tabular}




\section{A Proposed Magnetic Storm Analysis Based on Stock Market Tools}

Technical analysis is the process aiming at the possible estimation of future prices by analyzing past price data [70], using a set of empirical stock market analysis tools. Crucial factor towards achieving this goal is to identify the direction (upward, downward, or "sideways"-horizontal), duration, and strength of the price trend [79]. In order to identify those characteristics of trend, the use and combined interpretation of different tools of technical analysis is required [73,79]. The application of these tools is flexible and can be adapted to any time duration (from a few minutes up to months) [56]; however, the obtained results are considered more reliable in the case of short-term (in the scale of a few hours to a few days) analyses, compared to the ones obtained for long-term (in the scale of many months to a few years) ones [75]. Based on this fact and given that the duration of a typical MS ranges in the order of a few hours up to a few days, while the available data are hourly $D_{s t}$ values, a short-term study of the time evolution of the phenomenon, in analogy to stock markets, seems feasible.

In this paper, we attempt to apply a combination of three technical analysis tools to hourly $D_{s t}$ data variations. Specifically:

(i) The $S M A$, which has been calculated for $n=20$ hours (cf. Equation (1)), is used to identify the trend of $D_{s t}$ values and offers, albeit with some lag, quite reliable signs of upcoming changes in $D_{s t}$ values. Note that "if the slope is sharp, the trend is strong, and if the slope is shallow, the trend is weak; a flat or choppy SMA indicates a range-bound market" [71].

(ii) The Bollinger bands, calculated for an SMA of $n=20$ hours and $K=2$ (cf. Equations (2)-(4)), are used in order to provide a depiction of the range of variation of the $D_{s t}$ values. Observing the width of the bands and the movement of the $D_{s t}$ curve within or outside the bands, we draw conclusions for the volatility of $D_{s t}$ values as well as a rough qualitative assessment for the duration that this would have. When combined with other indicators, such as the RSI, the Bollinger bands become quite powerful, since RSI is "an excellent indicator with respect to overbought and oversold conditions" [67].

(iii) The RSI indicator, which has been calculated for $n=20$ hours and is a momentum indicator, is used to measure the speed and strength of the trend of $D_{s t}$ values. When the $R S I$ curve falls below 30 , this indicates that $D_{s t}$ values have been reduced considerably in a short period of time.

Through the application of these financial analysis tools to $D_{s t}$ time series, our aim is to identify similar features among the Dst time series during MSs and the financial time series in high volatility periods and, accordingly, formulate an analysis approach that could be employed in order to closely monitor the evolution of an MS. The here-proposed analysis approach was extracted after the analysis of $24 \mathrm{MSs}$ of all classes occurring from 1958 to 2015, shown in Table 1.

In the following, we describe the behavior of the considered technical analysis tools during the evolution of an MS, thus providing a way of application of these tools for the study of the temporal evolution of $D_{s t}$ time series. Specifically, we provide a detailed description of all the $D_{s t}$ time series features, in analogy to corresponding features of financial time series, that can be found during the onset, main development, and recovery phase of an MS, focusing on the temporal sequence in which they occur. The application of the proposed analysis approach on characteristic cases of MSs is demonstrated in Section 4.

After analyzing the $D_{s t}$ time series corresponding to all the MSs included in Table 1, we consider that it is appropriate to classify the features, which resulted from the application of the employed technical analysis tools and can be found during the onset, main development, and recovery of an MS into "main" and "secondary". The ones characterized as main are those which have been found to occur for all the examined cases of MSs, whereas the features characterized as secondary should be considered as features supporting the main ones, without, however, being expected to be found in all cases.

On one hand, the main features revealed during the analysis of the evolution of an MS are (M.i) the narrowing of the Bollinger bands; (M.ii) the downward crossing of 
the $S M A$ curve by the $D_{s t}$ curve; (M.iii) the steep downward slope of the RSI indicator; (M.iv) the downward crossing of the lower Bollinger band by the $D_{s t}$ curve; (M.v) the retreat of the RSI indicator in the oversold area (below 30); (M.vi) the steep downward slope of the $S M A$ curve; (M.vii) the RSI reaching a zero slope in the oversold area; (M.viii) the $D_{s t}$ curve moving away from the lower Bollinger band and the start of a gradual reduction in the width of Bollinger bands, as well as a local maximum at the upper Bollinger band; (M.ix) the $D_{s t}$ curve moving towards the SMA curve; (M.x) the exit of the RSI indicator from the oversold situation; (M.xi) the upward crossing of the $S M A$ curve by the $D_{s t}$ curve; (M.xii) the upward slope of the SMA curve; (M.xiii) the entrance of the RSI indicator to the overbought situation.

On the other hand, the secondary features include (S.i) the emergence of a "head fake"; (S.ii) a "divergence" between the $D_{s t}$ values and the RSI values at local maxima or minima; (S.iii) the emergence of a "failure swing"; (S.iv) chart patterns such as "head and shoulders" or "triangles"; (S.v) the $D_{s t}$ curve moving outside the Bollinger bands during its downward movement; (S.vi) the decline of the RSI indicator in oversold situation in combination with the downward crossing of the lower Bollinger band by the $D_{s t}$ curve; (S.vii) the $D_{s t}$ curve re-entrance within Bollinger bands when approaching the end of its downward movement; (S.viii) a local minimum of $D_{s t}$ values while being outside of the Bollinger bands followed by local minimum inside the bands.

In the following, we present an analysis approach based on the time series features that can be found during the evolution, namely the onset, main development, and recovery phase, of an MS by assessing the behavior of the three considered technical analysis tools. We point out that similar features are presented on a daily basis in the financial markets in a variety of financial assets. We employ all signs, main and secondary, focusing on the temporal sequence in which they occur. The analysis approach is presented in the form of three consecutive phases, each one consisting of a set of features organized in steps according to their order of occurrence. An illustrative example of application is given in parallel using a super-storm which occurred on 31/3/2001 with a peak $D_{s t}$ value of $-387 \mathrm{nT}$ (see Figure 1a, as well as line no. 13 of Table 1).

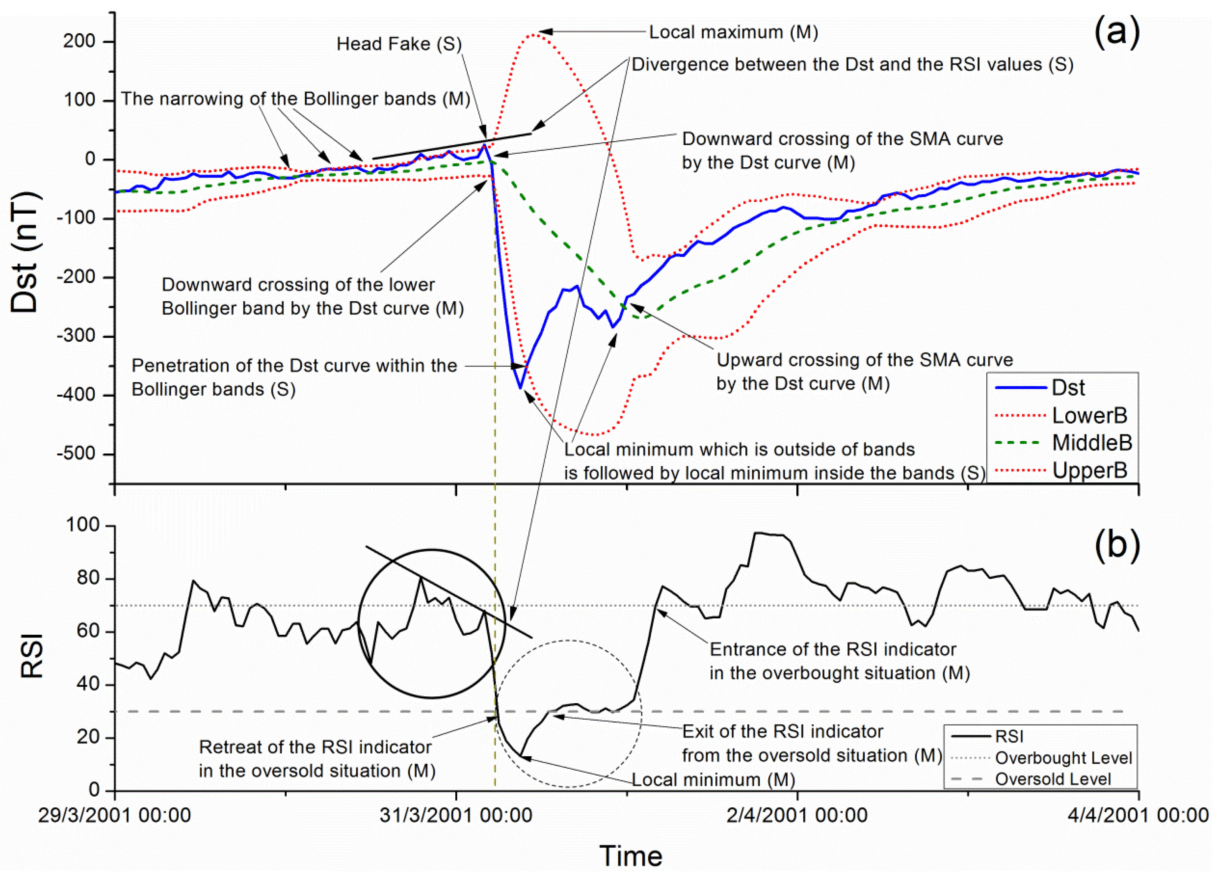

Figure 1. The evolution of an MS in terms of: (a) the $S M A$ and Bollinger bands, (b) the RSI indicator. The analyses results for a six-day period from 29 March 2001 00:00 (UT) to 4 April 2001 00:00 (UT) are presented as an example. Note that the appearing "(M)" and "(S)" signs refer to the main and secondary features, respectively, as classified in the main text. The areas of the RSI curve, marked by solid and dashed circles, include some secondary features, shown in detail in Figure 2. 

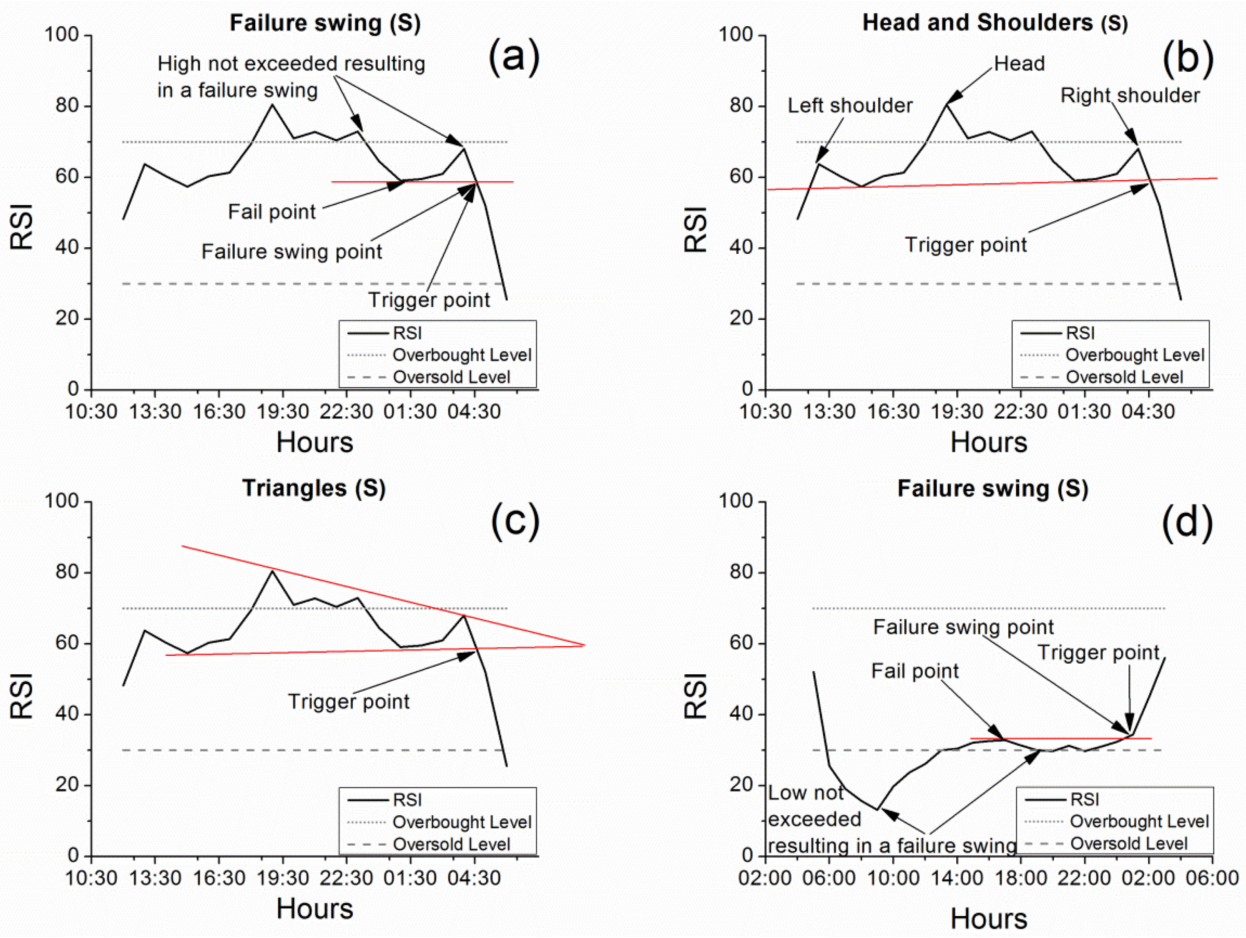

Figure 2. Detail of secondary features present in the areas of the RSI curve of Figure $1 \mathrm{~b}$ which are marked by solid (detailed in (a-c)) and dashed (detailed in (d)) circles. The examined time period lies between 30 March 2001 12:00 (UT) and 1 April 2001 03:00 (UT). (a,d): The red line shows the failure swing point [84]. (b): The red line, which is called "neckline", connects the lows of the two troughs between the three peaks. The line can slope up or down. The point at which the RSI value crosses the red line is often used as a final feature for the change of trend ("trigger point") [84]. (c): The horizontal support line is an imaginary line that acts as support for the RSI values. Once RSI values are below this line, it resists any upward movement of the RSI values. The downward-sloping top trend line is an imaginary line that acts as a layer of resistance for the RSI values [84].

\section{Phase I: Preparation}

(I.a) The first main feature that is presented before a possible upcoming MS is the narrowing of the Bollinger bands (M.i) (cf. Figure 1a). The narrowing of bands indicates very low volatility of the $D_{s t}$ values preceding a volatility breakout [73] and a corresponding extension of the bands. Immediately after the narrowing of the Bollinger bands, we assume that this will be followed by a higher volatility of $D_{s t}$ values compared to that observed during the previous period.

(I.b) In the majority of the analyzed $D_{s t}$ time series cases, it has been observed that after the narrowing of the bands and before the start of the downward movement of $D_{s t}$, which may evolve to an MS, some secondary features are found. Although such features should only be considered as supportive of the main ones, we consider these important to mention for completeness purposes. One of them is a local maximum of $D_{s t}$ curve which exceeds the upper Bollinger band. This local maximum, often referred to as "head fake" (S.i) (cf. Section 2.1.2), is a feature implying that the trend of the $D_{s t}$ curve in the coming hours will be downwards (see Figure 1a). In addition, quite often, just before the beginning of the downward movement of the $D_{s t}$ curve, a "divergence" (S.ii) between the $D_{s t}$ values and the RSI values appears (cf. Section 2.1.3, see Figure 1a,b), as well as a "failure swing" (S.iii) is observed (cf. Section 2.1.3, see solid cycle area in Figure 1b, and enlarged in Figure 2a), which are also features indicating a continuing downward trend of the $D_{s t}$ curve. Finally, during the same period, there have been observed, more rarely than the previous features, formulations in the RSI indicator known as "head and shoulders" or "triangles" (S.iv) (cf. Section 2.1.3, see solid cycle area in Figure $1 b$ and enlarged in Figure 2b,c, respectively). 


\section{Phase II: Main}

(II.a) The second main feature of a possible approaching MS is a downward crossing of $S M A$ curve by the $D_{s t}$ curve (M.ii), which is presented in the beginning of a downward trend of $D_{s t}$, as shown in Figure 1a. This is considered a very important feature, since it has been clearly identified before each one of the studied MSs. The downward movement of $D_{s t}$ usually starts a few hours earlier (cf. Figure 1a) because, as we already mentioned, the $S M A$ provides signs of trend change with a lag. Another main feature is the steep downward slope of the RSI indicator (M.iii) (Figure 1b). This is indicating that $D_{s t}$ curve is moving with high speed downwards, and consequently, the MS is in full deployment. The next very important feature, of the features sequence corresponding to the main phase of an MS, is the downwards crossing of the lower Bollinger band by the $D_{\text {st }}$ curve (M.iv) (cf. Figure 1a, the moment of crossing is denoted by the vertical dashed line). This usually happens shortly after the downwards crossing of $S M A$; however, sometimes these two features occur simultaneously. The downwards crossing of the lower Bollinger band by the $D_{s t}$ curve is considered a main feature, since it has been identified in all the analyzed MS cases.

(II.b) In the majority of them, the $D_{s t}$ curve, after crossing the lower Bollinger band, continues to move outside the bands during the entire time period of its downward movement (S.v). This behavior, according to technical analysis literature, is a very strong indication for the evolution of the phenomenon, since it implies a continuation of the current (downward in our case) trend [70]. However, since this is not always observed for MSs, it has been classified as a secondary feature. Note that in the differentiating cases after the downwards crossing of the lower Bollinger band by the $D_{s t}$ curve, the $D_{s t}$ curve continues moving for a while outside the bands but soon after it penetrates into the bands; however, it continues its downward movement very close, almost in parallel, to the lower Bollinger band.

(II.c) Another main feature of the deployment of the phenomenon during its main phase is the retreat of the RSI indicator in the oversold area (below 30) (M.v, see Figure 1b). Note that this has, several times, been observed to occur simultaneously to the downward crossing of the lower Bollinger band by the $D_{s t}$ curve mentioned in step (II.a) (observe the vertical dashed line in Figure 1a,b). During the same time period, we observe the downward slope of the SMA (M.vi); it has been observed that the steeper the slope is, the more intensive the storm is.

(II.d) The feature, which usually provides a rough, qualitative indication about the duration of the downward movement of the $D_{s t}$ curve, and, correspondingly, the duration of the MS, is the moment when the RSI indicator declines in the oversold situation with respect with the moment of the downward crossing of the lower Bollinger band by the $D_{s t}$ curve (S.vi) (observe the vertical dashed line in Figure 1a,b). Specifically, as it is mentioned in technical analysis literature, "when price touches the lower Bollinger band, and RSI is above 30, it is an indication that the trend should continue, if price touches the lower Bollinger band and RSI is below 30 (possibly approaching 20), the trend may reverse itself and move upward" [67]. This means that if we observe a simultaneous crossing (of the lower Bollinger band by the $D_{s t}$ curve and the 30 line by the RSI), the MS is expected to have a longer duration, while if the RSI drops below 30 after the crossing of the lower Bollinger band by the $D_{s t}$ curve, the storm is expected to have shorter duration. Since the expected duration of the downward movement of the $D_{s t}$ curve according to this criterion cannot be quantitatively estimated, while also in a small number of cases even a rough qualitative assessment was not possible (i.e., MSs expected, according to the specific criterion, to last long were of short duration and vice versa), the corresponding feature was classified as a secondary one. In the case presented in Figure 1, the RSI drops below 30 almost simultaneously to the downward crossing of the lower Bollinger band by the $D_{s t}$ curve, which indicates that the downwards movement of the $D_{s t}$ will not last long. In this specific case, the downwards movement of the $D_{s t}$ lasted for $3 \mathrm{~h}$. 


\section{Phase III: Recovery}

(III.a) The first main feature which is associated with the end of the phenomenon is the RSI curve reaching a zero slope in the oversold area (M.vii). In some cases, this feature might be found earlier than the time the $D_{s t}$ curve reaches its local minimum value. However, in most analyzed cases it has been observed that the RSI curve reaches zero slope in the oversold area concurrently with the minimum value of the $D_{s t}$ curve. If the $D_{s t}$ curve, after crossing the lower Bollinger band, was continuously moving outside the bands during the entire time period of its downward movement, then the re-entrance of the $D_{s t}$ curve back into the bands can be taken into consideration as a secondary feature of the end of the storm (S.vii). This, along with a local minimum reached by the RSI curve, indicates an upcoming upward move of $D_{s t}$.

(III.b) The following main feature is the $D_{s t}$ curve moving away from the lower Bollinger band while a gradual reduction in the width of Bollinger bands is observed, as well as a local maximum of the upper Bollinger band (M.viii), indicating a gradual reduction of the volatility of $D_{s t}$ values. At the same time, the $D_{s t}$ curve is moving towards the $S M A$ curve (M.ix), indicating the attenuation of the phenomenon.

(III.c) Next, the exit of the RSI indicator from the oversold situation (M.x) is a feature associated with the upcoming ending of the phenomenon. Then, the upward crossing of the $S M A$ curve by the $D_{s t}$ curve (M.xi) and the subsequent upward slope of the $S M A$ curve (M.xii) are main features of the end of the MS. During the same time period, two secondary features may be observed. The first of them, which might precede the exit of the RSI indicator from the oversold situation, is the occurrence of two local minima of the $D_{s t}$ curve, one outside the Bollinger bands, followed by a second inside the bands forming a $\mathrm{W}$-shaped curve (S.viii). The other secondary feature, which always follows the exit of the $R S I$ indicator from the oversold situation, is a failure swing in the RSI curve, implying also the upward trend of $D_{s t}$ (S.iii) (cf. Section 2.1.3, see dashed cycle area in Figure 1b, and enlarged in Figure 2d).

(III.d) The final feature found during the termination of the phenomenon is the entrance of the RSI indicator to the overbought situation (M.xiii), which implies that the upward trend of the $D_{s t}$ curve is strong before it returns to the quiet conditions.

In summary, each one of the abovementioned phases presents at least the following features, in the specific sequence per phase and step (indicating also the corresponding notation for numbering phases, phase steps, and main and secondary features):

\section{Phase I:}

- $\quad$ Step (I.a): Narrowing of the Bollinger bands in quiet conditions (M.i).

\section{Phase II:}

- $\quad$ Step (II.a): Downward crossing of the $S M A$ curve by the $D_{s t}$ curve (M.ii).

- Step (II.a): Steep downward slope of the RSI indicator (M.iii).

- $\quad$ Step (II.a) Downward crossing of the lower Bollinger band by the $D_{s t}$ curve (M.iv).

- $\quad$ Step (II.c): Retreat of the RSI indicator in the oversold area (below 30) (M.v).

- $\quad$ Step (II.c): Steep downward slope of the $S M A$ curve (M.vi).

\section{Phase III:}

- $\quad$ Step (III.a): Zero slope of the RSI curve in the oversold area (M.vii).

- $\quad$ Step (III.b): The $D_{s t}$ curve moving away from the lower Bollinger band and the start of a gradual reduction in the width of Bollinger bands, as well as a local maximum at the upper Bollinger band (M.viii).

- $\quad$ Step (III.b): The $D_{s t}$ curve moving towards the $S M A$ curve (M.ix).

- $\quad$ Step (III.c): Exit of the RSI indicator from the oversold situation (M.x).

- $\quad$ Step (III.c): Upward crossing of the $S M A$ curve by the $D_{s t}$ curve (M.xi).

- Step (III.c): Upward slope of the $S M A$ curve (M.xii).

- Step (III.d): Entrance of the RSI indicator to the overbought situation (M.xiii).

It is highlighted that all of these features have been found to occur for all the examined cases of MSs. 


\section{Analysis Results}

The applicability of the analysis approach proposed in Section 3 for the analysis of the $D_{s t}$ time series during MSs based on stock market (technical analysis) tools is examined in detail on four characteristic cases of MSs. Moreover, Table 1 shows which of the considered features (per phase and step) were identified for each one of the 24 analyzed MSs. The corresponding informative plots, which summarize the analyses results for each one of the MSs listed in Table 1, are also provided as online supplementary material.

\subsection{First Case Study}

The first case we examine is that of the storm that occurred on 22 October 1999 (see line no. 10 of Table 1); the analyses results are portrayed in Figure 3. The evolution of the specific MS in terms of the phases and corresponding steps described in Section 3 follows:

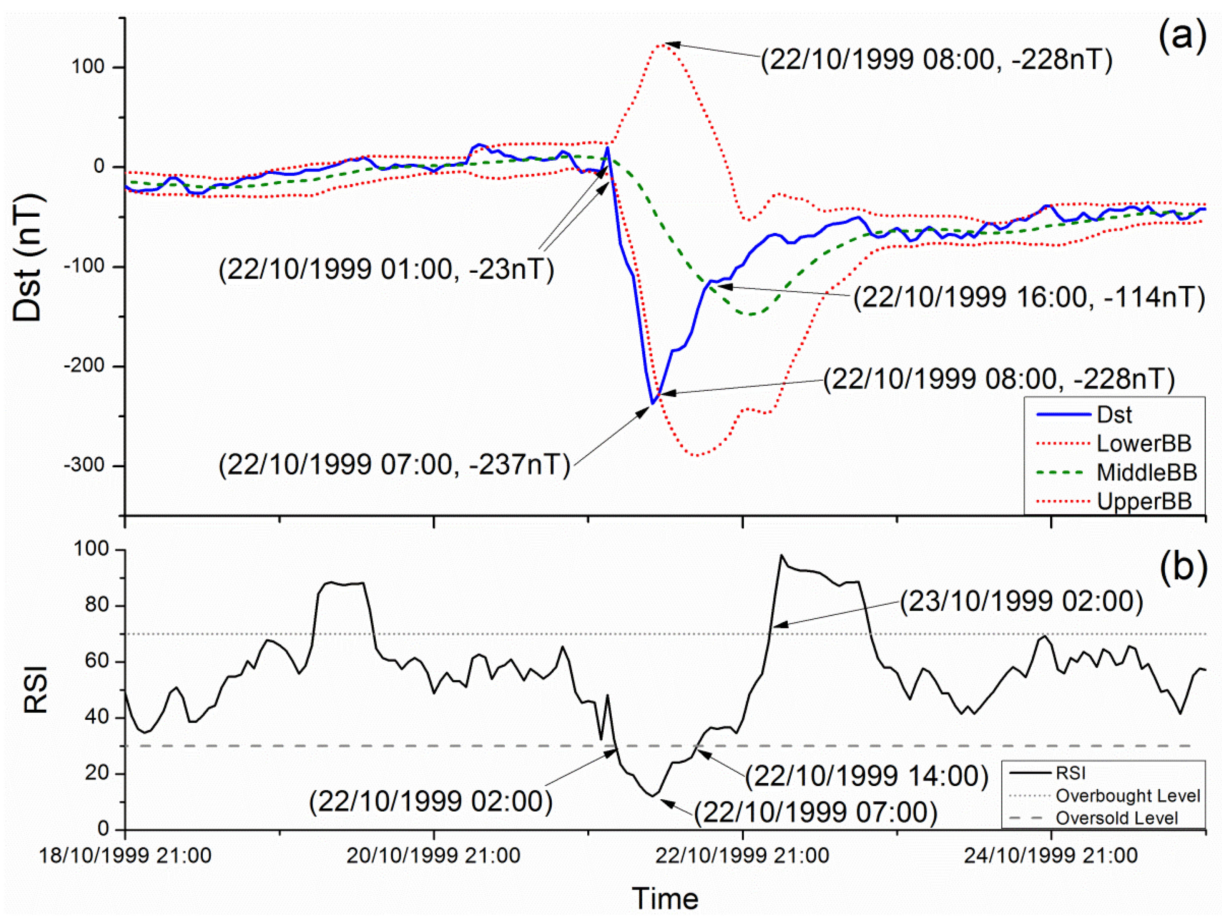

Figure 3. The evolution of an MS which occurred in 1999 in terms of (a) the SMA and Bollinger bands, and (b) the RSI indicator. The analyses results for a seven-day period from 18 October 1999 21:00 (UT) to 25 October 1999 21:00 (UT) are presented. The exact time and $D_{s t}$ value for which specific features were found are marked on the figure using arrows.

\section{Phase I: Preparation}

In Figure 3, we observe a (prolonged) narrowing of Bollinger bands, from 18 October 1999 21:00 until 22 October 1999 01:00. As already mentioned in step (I.a) of Section 3, this is a first feature for a possible upcoming MS. Note that the secondary features described in step (I.b) are not observed in the specific case.

\section{Phase II: Main}

Step (II.a): A few hours later, on 22 October 1999 01:00, we can see that two main features appear simultaneously, namely the downward crossing of the $S M A$ curve and the lower Bollinger band by the $D_{s t}$ curve. At this point, we should mention that the RSI indicator is also moving with a steep downward slope towards the oversold (under 30) area, indicating that the $D_{s t}$ values move with high speed downwards.

Step (II.b): As long as the $D_{s t}$ curve moves downward outside the Bollinger bands, a continuation of the current (downward) trend is implied.

Step (II.c): One hour later, on 22 October 1999 02:00, the RSI indicator retreats below 30 , while the $D_{s t}$ value is $-77 \mathrm{nT}$. During the next five hours, the downward movement of 
$D_{s t}$ continues, while in parallel, the $S M A$ curve retreats with steep slope, concluding the sequence of main features related to the deployment of the MS.

Step (II.d): At this point, we should note that at the moment when the $D_{s t}$ curve downward crossed the lower Bollinger, the RSI indicator had not yet reached its lower threshold value of 30 . This, as it has been observed in the majority of the examined MS cases (cf., Section 3), means that the downward movement of the $D_{s t}$, and consequently the MS, is expected, as a rough qualitative assessment, to last for a long time, provided that the RSI indicator finally retreats below 30 , as it indeed happens in our case.

\section{Phase III: Recovery}

Step (III.a): On 22 October 1999 07:00, concurrently with the minimum value of the $D_{s t}$ curve, the RSI curve has almost zero slope verifying the reversing of the downward trend of the $D_{s t}$ curve.

Step (III.b): On 22 October 1999 08:00, while the $D_{s t}$ curve starts the upward movement, it enters again into the Bollinger bands, while at the same time the upper Bollinger band presents a local maximum, enhancing the features associated with the definite completion of the downward movement of the $D_{s t}$ curve. Subsequently, we observe that the $D_{s t}$ curve, as it moves upwards, moves towards the SMA curve, while at the same time moves away from the lower Bollinger band. Note that, in parallel, the width of Bollinger bands is gradually reduced, indicating a gradual reduction of the volatility of $D_{s t}$ values.

Step (III.c): After that, we identify two more main features related with the ending of the phenomenon: first, the RSI indicator exits the oversold situation on 22 October 1999 14:00, while two hours later, the upward crossing of the $S M A$ curve by the $D_{s t}$ curve happens. Note that the secondary features of step (III.c) described in Section 3 were not observed in the specific MS case.

Step (III.d): Finally, on 23 October 1999 02:00, the RSI indicator enters the overbought situation, signifying the conclusion of the MS.

\subsection{Second Case Study}

Next, we examine a storm which occurred on 8 November 2004 (see line no. 18 of Table 1), while the corresponding analyses are shown in Figure 4.

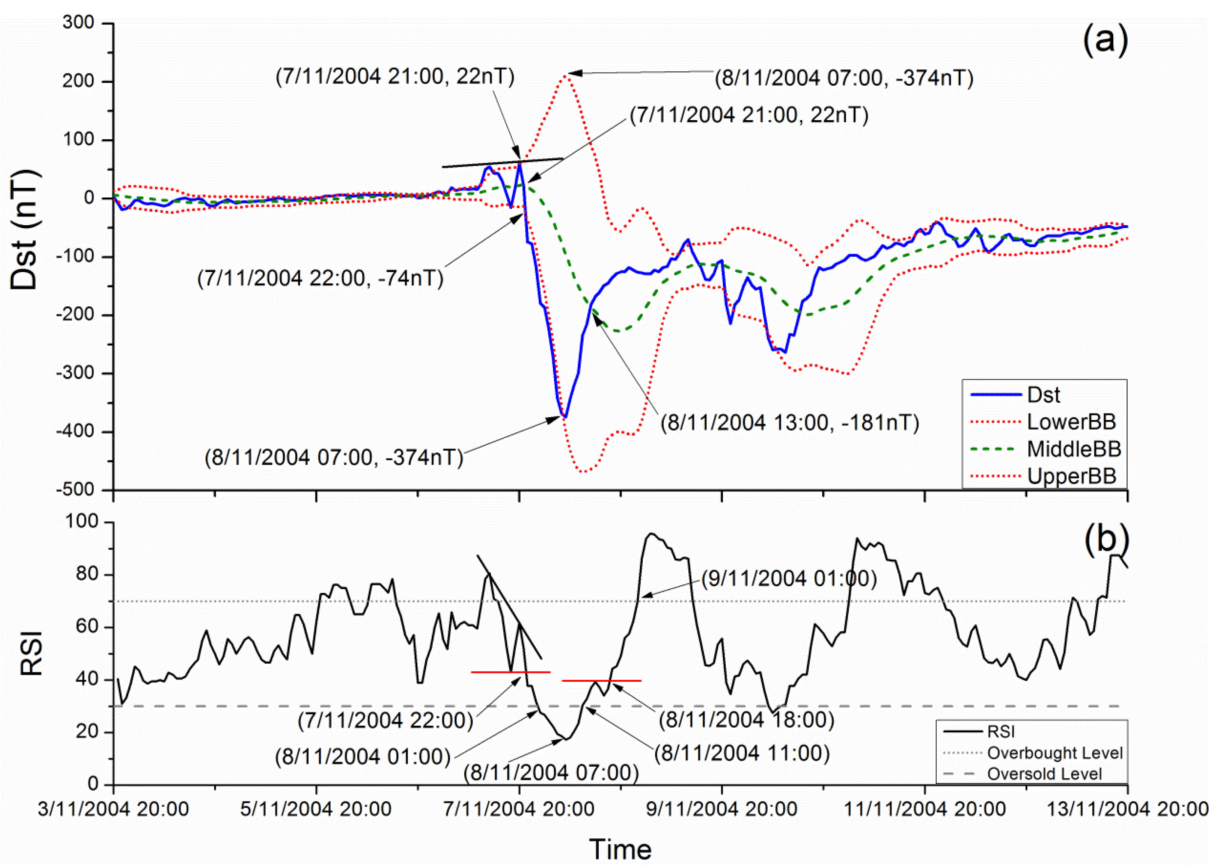

Figure 4. The evolution of an MS which occurred in 2004 in terms of (a) the SMA and Bollinger bands, and (b) the RSI indicator. The analyses results for a ten-day period from 3 November 2004 20:00 (UT) to 13 November 2004 20:00 (UT) are presented. The exact time and $D_{s t}$ value for which specific features were found are marked on the figure using arrows. 


\section{Phase I: Preparation}

Step (I.a): First, we observe that there is a (prolonged) narrowing of the Bollinger bands from 3 November 2004 20:00 until 06 November 2004 19:00.

Step (I.b): At 21:00 of the next day, we can see two secondary features of the preparation phase, namely the head fake and the divergence between the $D_{s t}$ curve and the RSI indicator. Moreover, in parallel, the RSI indicator curve forms a failure swing. Although these are secondary features, they enhance the evidence in favor of an upcoming MS, since they imply a continuing downward movement of $D_{s t}$.

\section{Phase II: Main}

Step (II.a): Right after this, the downward crossing of the $S M A$ curve by the $D_{s t}$ curve is observed, while one hour later the downward movement of the $D_{s t}$ curve continues and crosses the lower Bollinger band. Moreover, the RSI indicator is moving with a steep downward slope towards the oversold (under 30 ) area, indicating that the $D_{s t}$ values move with high speed downwards.

Step (II.b): At this point, we observe that the $D_{\text {st }}$ curve moves downward outside the Bollinger bands. As long as this is satisfied, a continuation of the current (downward) trend is implied.

Step (II.c): On 08 November 2004 01:00, the RSI indicator curve retreats below 30. During the next six hours, the downward movement of $D_{s t}$ continues, while in parallel, the $S M A$ curve retreats with steep slope.

Step (II.d): At this point we should take into account that the RSI indicator reached the low threshold value of 30 later than the moment when the $D_{s t}$ curve crossed downwards the lower Bollinger. In other words, the RSI indicator had a value higher than 30 when the $D_{s t}$ curve crossed downwards the lower Bollinger, indicating, as a rough qualitative assessment, that the downward movement of the $D_{s t}$ is expected to last for a long time.

\section{Phase III: Recovery}

Step (III.a): On 08 November 2004 07:00, we observe three features associated with the upcoming change of the $D_{s t}$ curve move to an upwards one; namely, the RSI curve slope almost reaches zero, while at the same time, the $D_{s t}$ curve reaches its local minimum value and penetrates into the Bollinger bands.

Step (III.b) At the same time, a local maximum is observed in the upper Bollinger band, indicating that the downwards trend of the $D_{s t}$ curve will soon be changed to an upwards one. Indeed, one hour later the $D_{s t}$ curve trend changes to upwards. From this point on, the $D_{s t}$ curve moves upwards approaching the $S M A$ curve, departing from the lower Bollinger band, while the bands gradually narrow.

Step (III.c): Then, the RSI indicator gradually moves upwards, leading to a feature found near the ending of the MS: the exit of the RSI indicator from the oversold situation which occurs on 8 November 2004 11:00. Following that, the next main feature is the upward crossing of the $S M A$ curve by the $D_{s t}$ curve, which takes place on 8 November 2004 13:00. From this point on, although with a certain delay, the $S M A$ curve develops an upwards slope. Five hours later, on 8 November 2004 18:00, a secondary feature, a failure swing, appears in the RSI indicator curve, enhancing the evidence in favor of the upward trend of the $D_{s t}$ curve.

Step (III.d): Finally, the upcoming definite conclusion of the MS is signified by the entrance of the RSI indicator into the overbought situation on 9 November 2004 01:00.

It is finally noted that for the specific time period presented in Figure 4, one can observe that $\sim 2$ days after the above-analyzed MS, and while $D_{s t}$ has not yet reached quiet levels, a second weaker MS, but still an intense event (minimum $D_{s t}$ value - $250 \mathrm{nT}$ ), took place. While one could identify some of the technical analysis features (presented in Section 3) which, according to the proposed analysis approach, are found during the evolution of an MS, it is not possible to identify the complete sequence of main features. Therefore, we have to mention that in this case, the proposed analysis approach is not able to discriminate between the two sequentially appearing MSs. 


\subsection{Third Case Study}

The third MS analyzed in terms of technical analysis tools is a storm which occurred on 26 May 1967 (see line no. 8 of Table 1), while the corresponding analyses are shown in Figure 5. For the specific MS, we can identify the following sequence of features associated with its evolution by short-term analysis.

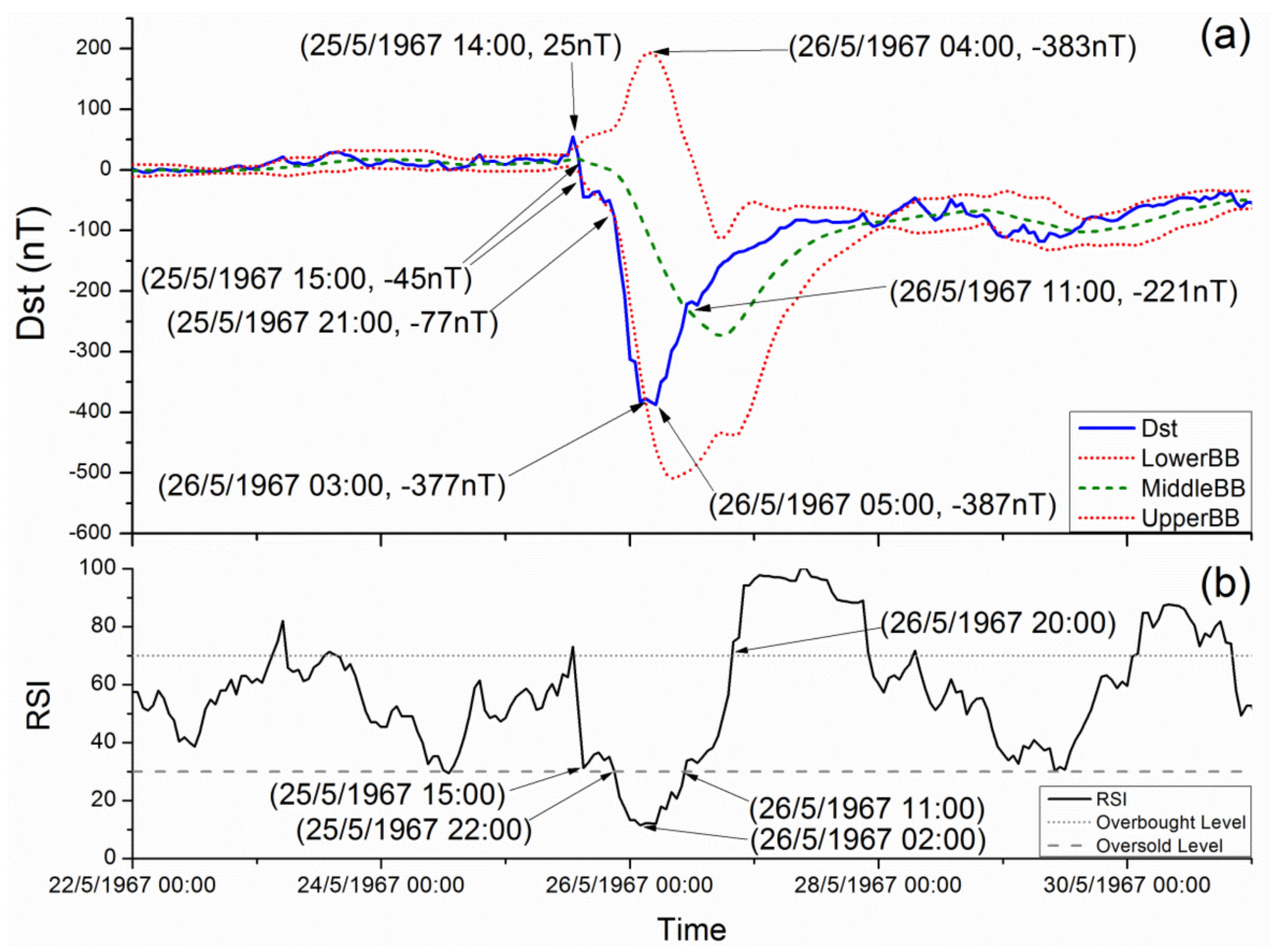

Figure 5. The evolution of an MS which occurred in 1967 in terms of (a) the SMA and Bollinger bands, and (b) the RSI indicator. The analyses results for a nine-day period from 22 May 1967 00:00 (UT) to 31 May 1967 00:00 (UT) are presented. The exact time and $D_{s t}$ value for which specific features were found are marked on the figure using arrows.

\section{Phase I: Preparation}

Step (I.a): From 22 May 1967 00:00 up to 25 May 1967 12:00, we observe a prolonged narrowing of the Bollinger bands, the first main feature of an upcoming MS.

Step (I.b): On 25 May 1967 14:00, we observe that a head fake is formed over the upper Bollinger band, which is a secondary feature indicating an upcoming downward trend of the $D_{s t}$ curve. Note that this is the only secondary feature that was identified at this step for the specific storm.

\section{Phase II: Main}

Step (II.a): The expected downward trend of the $D_{s t}$ curve indeed happened one hour later, on 25 May 1967 15:00, when the $D_{s t}$ curve simultaneously crossed downwards both the SMA curve and the lower Bollinger band. Both these crossings are main features of the beginning of an MS. Turning now to the RSI indicator, we can see that although it was moving with a steep downward slope towards the oversold situation, indicating a high downward speed for $D_{s t}$ values, it finds support at the 30 level. During the next five hours, the $D_{s t}$ curve moves inside the Bollinger bands, close to the lower band. However, the width of the bands continues to expand. On 25 May 1967 21:00 we observe that the $D_{s t}$ curve crosses once more the lower Bollinger band downwards. Note that between these two downward crossings of the lower Bollinger band, the $D_{s t}$ curve moves inside the bands, i.e., step (II.b) has not yet been observed. As already mentioned in Section 3, this step corresponds to a secondary feature which is not always observed after a downwards crossing of the lower Bollinger band by the $D_{s t}$ curve, so we do not pay any special 
attention to this fact. After the second crossing of the lower Bollinger band, we also notice that the RSI indicator moves with a steep downward slope, which is gradually reducing.

Step (II.b): From 25 May 1967 21:00 onwards, the $D_{s t}$ curve remains outside the Bollinger bands, indicating a continuation of its current (downwards) trend.

Step (II.c): The RSI indicator again moves downwards to the oversold situation to retreat below the 30 level one hour later. At the same time, we note that the SMA curve gradually begins to move downwards with steep slope, indicating a strong downwards trend for $D_{s t}$.

Step (II.d): Given that the $D_{\text {st }}$ curve downward crossed the lower Bollinger band before the RSI indicator retreated below 30, we expect, as a rough qualitative assessment, that the downward movement of $D_{s t}$ until it reaches its lowest value will last for a long time (in the specific case, this lasted for $6 \mathrm{~h}$ ).

\section{Phase III: Recovery}

Step (III.a): On 26 May 1967 02:00, the RSI curve reaches almost zero slope, indicating that the downward trend of the $D_{s t}$ curve is soon expected to be reversed to an upward trend. One hour later, at 03:00, we can see that the $D_{s t}$ curve penetrates inside the Bollinger bands, which is a secondary feature enhancing the possibility that the $D_{s t}$ trend is soon expected to be upward.

Step (III.b): One hour later, on 25 May 1967 04:00, a local maximum of the upper Bollinger band is observed, which is a main feature also informing us about the upcoming upwards trend of the $D_{s t}$ curve. Next, the $D_{s t}$ curve moves towards the $S M A$ curve and away from the lower Bollinger band, while, in parallel, the width of the bands is gradually reducing.

Step (III.c): On 26 May 1967 11:00, two main features appear, simultaneously related to the ending of the phenomenon. Specifically, the $D_{s t}$ curve upward crosses the $S M A$ curve, and, soon after, the $S M A$ develops an upwards slope, while the RSI indicator exits the oversold situation.

Step (III.d): Finally, on 26 May 1967 20:00, we observe the RSI indicator entering the overbought situation, which signifies the definite completion of the phenomenon.

\subsection{Fourth Case Study}

The last MS case is an intense storm which occurred on 25 October 2011 (see line no. 23 of Table 1); the corresponding analyses are shown in Figure 6. The evolution of the specific MS in terms of the phases and corresponding steps described in Section 3 follows:

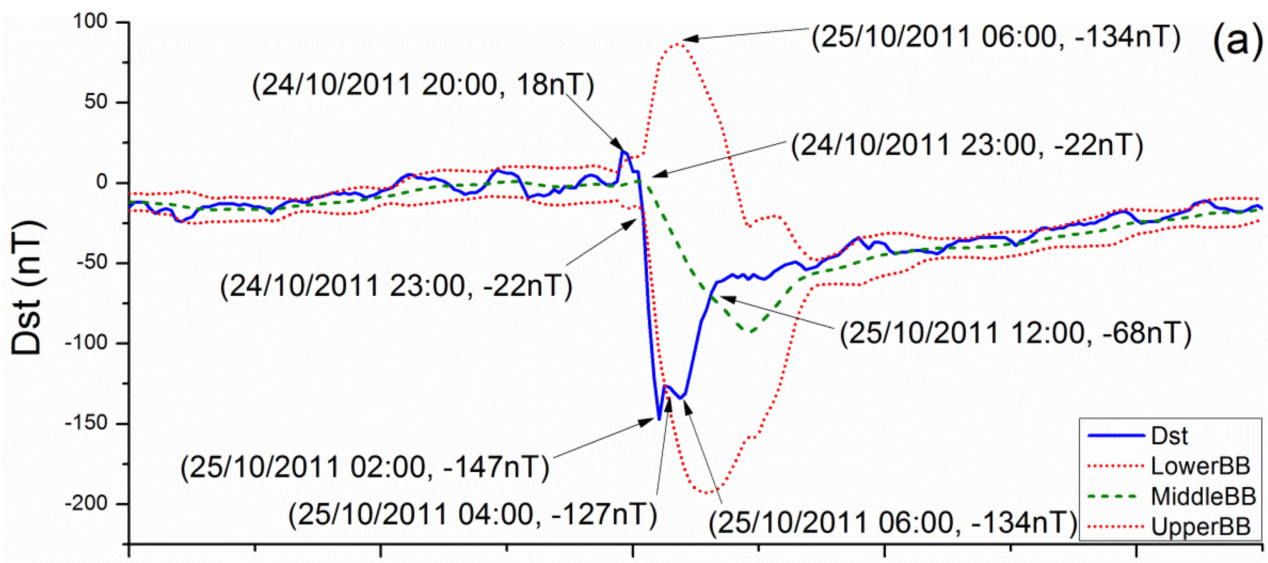

Figure 6. Cont. 


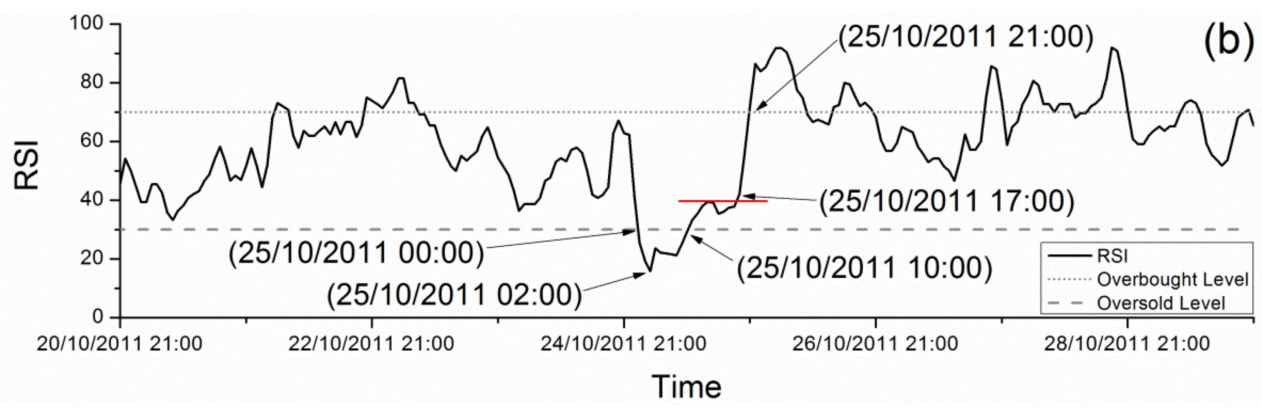

Figure 6. The evolution of an MS which occurred in 2011 in terms of (a) the SMA and Bollinger bands, and (b) the RSI indicator. The analyses results for a nine-day period from 20 October 2011 21:00 (UT) to $29 / 10 / 2011$ 21:00 (UT) are presented. The exact time and $D_{s t}$ value for which specific features were found are marked on the figure using arrows.

\section{Phase I: Preparation}

Step (I.a): From 20 October 2011 21:00 up to 24 October 2011 19:00, we observe a prolonged narrowing of the Bollinger bands, which, as already mentioned in Section 3, is a main feature observed before an upcoming MS.

Step (I.b): On 24 October 2011 20:00, although, until then, the $D_{s t}$ curve was moving mainly within Bollinger bands, we observe a head fake which is expected before an upcoming downtrend in the $D_{s t}$ curve. Other secondary features, of the ones corresponding to the specific step in Section 3, were not observed for the specific MS.

\section{Phase II: Main}

Step (II.a): A few hours later, on 24 October 2011 23:00, we can see that two main features appear simultaneously, namely the downward crossing of the $S M A$ curve and the lower Bollinger band by the $D_{s t}$ curve. We also observe that the $R S I$ indicator is moving with a steep downward slope towards the oversold (under 30) area, indicating that the $D_{s t}$ values move with high speed downwards.

Step (II.b): After the crossing of the lower Bollinger band by the $D_{s t}$ curve, the $D_{s t}$ curve moves downward outside the Bollinger bands, signifying a continuation of the current (downward) trend.

Step (II.c): On 24 October 2011 00:00, the RSI indicator enters the oversold situation, while, from this point on, the $S M A$ curve moves downwards with a steep slope.

Step (II.d): This specific MS is an example for which step (II.d) does not provide a correct assessment for the duration of the MS. Although the retreat of the RSI indicator into the oversold situation was delayed with respect to the moment when the downward crossing of the lower Bollinger band by the $D_{s t}$ curve occurred, the duration of the downward movement of the $D_{s t}$ curve, and correspondingly the duration of the MS, was not long. Remember that the specific feature was classified as a secondary one, exactly due to the reason that there are MS cases, even though they are very few, for which it does not provide even a rough qualitative assessment for their expected duration, in addition to the fact that it is not possible to provide a quantitative assessment for the expected duration, only a rough qualitative assessment.

\section{Phase III: Recovery}

Step (III.a): On 25 October 2011 02:00, we observe that the RSI indicator almost reaches zero slope, indicating that the $D_{s t}$ curve will possibly move upwards during the following hours. The $D_{s t}$ curve also reaches its local minimum value then, while, two hours later, the $D_{s t}$ curve enters back into the Bollinger bands, one more feature observed when the phenomenon is led to its completion.

Step (III.b): Following that, on 25 October 2011 06:00, we observe a local maximum of the upper Bollinger band, suggesting the upcoming reduction of $D_{s t}$ values' volatility, as well as a secondary feature, usually observed later, and for this reason described as part of step (III.c), the occurrence of two local minima of the $D_{s t}$ curve, one outside the Bollinger bands followed by a second inside the bands forming a W-shaped curve. During the next 
hours, the $D_{s t}$ curve develops an upwards slope towards the $S M A$ curve, while at the same time, the width of the Bollinger bands is gradually reduced and the $D_{s t}$ curve moves away from the lower Bollinger band, all implying a return to normal (quiet) $D_{s t}$ values.

Step (III.c) On 25 October 2011 10:00, the RSI curve exits the oversold situation, while two hours later, the $D_{s t}$ curve upward crosses the $S M A$ curve, which then moves with an upwards slope, complementing the features related to the ending of the phenomenon. Moreover, on 25 October 2011 17:00, a failure swing is observed, which is a secondary feature.

Step (III.d): The final recovery phase feature, signifying the conclusion of the MS, occurs on 25 October 2011 21:00, when the RSI indicator enters the overbought situation.

\section{Discussion-Conclusions}

In the frame of complex systems, we studied the time series of $D_{s t}$ in terms of the empirical financial analysis method known as technical analysis, focusing on the temporal evolution of MSs. Specifically, we employed the combination of three very popular tools of technical analysis, the simple moving average $(S M A)$, the Bollinger bands, and the relative strength index $(R S I)$. The goal of this exploratory study was to formulate an analysis approach of $D_{s t}$ time series during the evolution of MSs in analogy to asset price time series analysis in high volatility periods.

This analysis approach was developed after the analysis of more than 20 MS events, revealing all the technical analysis features (appearing in financial time series during high volatility periods, e.g., $[67,73])$ which, in specific temporal sequence of occurrence, appear associated with the onset, main development, and recovery phase of an MS. It is emphasized that, in the proposed analysis approach, the feature sequence is important in the evolution of an MS, and not merely each feature by itself. For example, a downward crossing of the $S M A$ curve by the $D_{s t}$ curve, per se, without the preceding and following main features, does not imply a new MS. The applicability of the proposed analysis approach was presented in detail for four characteristic cases of MSs, while the results for the whole set of 24 analyzed MSs verify the repeatability of the proposed features' sequences.

We focus on the fact that the results of this study enhance the view that quantitative analysis methods may successfully be transferred between finance and geophysical systems. Our results show that $D_{s t}$ time series around the occurrence of MSs can be successfully analyzed by the same empirical tools applied to financial time series for investment analysis.

In general, when a new MS is developing, the sequence of features described by the proposed analysis approach is repeated. However, clearly, the presented analysis approach is not suggested as a method for the early detection of MSs. The main shortcomings for such an application are mentioned in the following. Magnetic storms are not always preceded by quiet conditions and, in such cases, the narrowing of the Bollinger bands feature before an MS may not be clearly identified or even not identified at all, while on the other hand, a narrowing of the Bollinger bands may be observed in quiet conditions without an MS to follow, and it is not possible to predict whether double or multiple storms will occur. Moreover, it is not possible to predict what the minimum value of $D_{s t}$ will be, or whether the minimum $D_{s t}$ value will exceed some specific threshold, e.g., $-50 \mathrm{nT},-100 \mathrm{nT}$, etc.; only the short-term trend is inferred. As a result, the described sequence of features may be observed even in the case of variations that do not exceed $-50 \mathrm{nT}$. Additionally, it is not possible to predict when the $D_{\text {st }}$ minimum will occur or to provide a quantitative assessment for the duration of an MS. Characteristic examples highlighting these shortcomings are the following: the MSs no. 20-21 of Table 1 (see also online supplementary material) where the two MSs that happened with $\sim 8$ days distance and had minimum $D_{s t}$ values $-184 \mathrm{nT}$ and $-122 \mathrm{nT}$, respectively, presented the same main features of the $D_{s t}$ time series. The variation of the $D_{s t} \sim 2$ days before the MS no. 17 of Table 1 (see also online supplementary material), despite the fact that it reaches a minimum value of only $\sim-30 \mathrm{nT}$, presents most of the main features observed in all the analyzed 
MSs. The $D_{s t}$ time series of the second case study (Figure 4) presents a second minimum of the order of $-200 \mathrm{nT}$, around which the considered features are not all clearly found.

These shortcomings call for further investigation of the proposed use of the considered technical analysis tools in the study of MSs. This should primarily focus on the tuning of analysis parameters based on extensive statistics resulting from the application of the specific tools for long enough time periods, e.g., for the last two solar cycles. Note that the considered technical analysis methods were applied to $D_{s t}$ time series directly adopting mutatis mutandis in terms of sampling rate scale, the parameter values usually employed for the analyses of financial time series. Specifically, the usually employed parameter values for the calculation of $S M A$ and Bollinger bands when applied to daily stock market share data $(n=20, K=2)$ were also used for the case of hourly $D_{s t}$ data.

Moreover, after an appropriate tuning of the proposed analysis' parameters, we consider the worth of investigating its combination with other statistical and complex systems time series analysis methods, such as different kind of entropies, Hurst exponent, fractal analysis, and log-periodic corrections. Furthermore, by incorporating solar wind data in the proposed combined multi-method analysis scheme, we may improve the diagnostics of the coupled solar wind-magnetosphere system and, consequently, the mitigation of space weather hazards. Although this is outside the scope of this specific work, it is in our near future plans to elaborate such a study.

As already clarified, the here-presented study followed the empirical way of analyzing financial time series for the analysis of $D_{s t}$ time series, trying to identify features also used in financial time series, which could be associated with the temporal evolution of an MS. In a next step, one could focus on the interpretation of the observed behavior of the considered financial tools, in terms of the physics of the magnetosphere. Such a study could, on one hand, increase the effectiveness of the proposed analysis approach for the study of MSs, and, on the other hand, offer ideas in order to better understand stock market processes.

It has been established that natural hazards may result in geospace perturbations. For instance, it has been suggested that ionospheric perturbations could be attributed to earthquake events [85-88]. The promising results from the application of financial analysis tools to geomagnetic activity index time series, regarding the study of geomagnetic perturbations related to an MS, may also offer a useful framework of technical analysis for the study of geospace perturbations related to other natural hazards (e.g., earthquakes, tsunamis etc.).

Supplementary Materials: The following are available online at https:/ / www.mdpi.com/article/ $10.3390 /$ geosciences $11060239 / \mathrm{s} 1$ : The following 23 figures, showing the analysis of the magnetic storms (MS) included in Table 1, are available online at https:/ /www.mdpi.com/article/10.3390/ geosciences11060239/s1, where MS \# is the one appearing in Table 1, Figure S1: MS \#1, Figure S2: MS \#2, Figure S3: MS \#3, Figure S4: MS \#4, Figure S5: MS \#5, Figure S6: MS \#6, Figure S7: MS \#7, Figure S8: MS \#8, Figure S9: MS \#9, Figure S10: MS \#10, Figure S11: MS \#11, Figure S12: MS \#12, Figure S13: MS \#13, Figure S14: MS \#14, Figure S15: MS \#15, Figure S16: MS \#16, Figure S17: MS \#17, Figure S18: MS \#18, Figure S19: MS \#19, Figure S20: MS \#20-21, Figure S21: MS \#22, Figure S22: MS \#23, Figure S23: MS \#24. In each figure, the evolution of the corresponding magnetic storm is illustrated in terms of: (upper graph) the SMA and Bollinger bands, and (lower graph) the RSI indicator. The exact time and $D_{s t}$ value for which specific features were found are marked on the figure using arrows.

Author Contributions: Conceptualization, P.I.Z., S.M.P., and K.E.; methodology, S.M.P. and P.I.Z.; software, P.I.Z.; formal analysis, P.I.Z.; investigation, P.I.Z., S.M.P., and G.B.; data curation, G.B.; writing — original draft preparation, P.I.Z. and S.M.P.; writing—review and editing, P.I.Z., S.M.P., G.B., and K.E.; supervision, S.M.P. All authors have read and agreed to the published version of the manuscript.

Funding: This research received no external funding.

Data Availability Statement: The $D_{s t}$ index data used in this study are available at http:/ /wdc.kugi. kyoto-u.ac.jp/ (last accessed on 31 May 2021). 
Acknowledgments: We acknowledge the Kyoto World Data Center (WDC) for Geomagnetism and the observatories that produce and make the $D_{s t}$ index. We would like to thank the anonymous reviewers of this paper for their constructive comments.

Conflicts of Interest: The authors declare no conflict of interest.

\section{References}

1. Tsallis, C. Introduction to Nonextensive Statistical Mechanics: Approaching a Complex World; Springer: New York, NY, USA, 2009.

2. Picoli, S.; Mendes, R.; Malacarne, L.; Papa, A. Similarities between the dynamics of geomagnetic signal and heartbeat intervals. Europhys. Lett. 2007, 80, 50006. [CrossRef]

3. De Arcangelis, L.; Godano, C.; Lippiello, E.; Nicodemi, M. Universality in solar flare and earthquake occurrence. Phys. Rev. Lett. 2006, 96, 051102. [CrossRef]

4. Kossobokov, V.; Keillis-Borok, V.; Cheng, B. Similarities of multiple fracturing on a neutron star and on Earth. Phys. Rev. E 2000, 61, 3529-3533. [CrossRef]

5. Sornette, D.; Helmstetter, A. Occurrence of finite-time singularities in epidemic models of rupture, earthquakes and starquakes. Phys. Rev. Lett. 2002, 89, 158501. [CrossRef]

6. Abe, S.; Suzuki, N. Statistical similarities between internetquakes and earthquakes. Phys. D 2004, 193, 310-314. [CrossRef]

7. Fukuda, K.; Nunes, L.; Stanley, H. Similarities between communication dynamics in the Internet and the automatic nervous system. Europhys. Lett. 2003, 62, 189-195. [CrossRef]

8. Peters, O.; Hertlein, C.; Christensen, K. A complexity view of rainfall. Phys. Rev. Lett. 2002, 88, 018701. [CrossRef]

9. Bar-Yam, Y. Dynamics of Complex Systems; Addison-Wesley: Reading, MA, USA, 1997.

10. Potirakis, S.M.; Zitis, P.I.; Eftaxias, K. Dynamical analogy between economical crisis and earthquake dynamics within the nonextensive statistical mechanics framework. Phys. A 2013, 392, 2940-2954. [CrossRef]

11. Vicsek, T. The bigger picture. Nature 2002, 418, 131. [CrossRef]

12. Stanley, H. Scaling, universality, and renormalization: Three pillars of modern critical phenomena. Rev. Mod. Phys. 1999, 71, S358-S366. [CrossRef]

13. Stanley, H. Exotic statistical physics: Applications to biology, medicine, and economics. Phys. A 2000, 285, 1-17. [CrossRef]

14. Sornette, D. Predictability of catastrophic events: Material rupture, earthquakes, turbulence, financial crashes, and human birth. Proc. Natl. Acad. Sci. USA 2002, 99, 2522-2529. [CrossRef]

15. Vicsek, T. A question of scale. Nature 2001, 411, 421. [CrossRef] [PubMed]

16. Mantegna, R.N.; Stanley, H.E. Introduction to Econophysics: Correlations and Complexity in Finance; Cambridge University Press: Cambridge, UK, 2007.

17. Sornette, D. Why Stock Markets Crash: Critical Events in Complex Financial Systems; Princeton University Press: Princeton, NJ, USA, 2003.

18. Sornette, D. Critical market crashes. Phys. Rep. 2003, 378, 1-98. [CrossRef]

19. Yan, W.; Woodard, R.; Sornette, D. Diagnosis and prediction of rebounds in financial markets. Phys. A 2012, 391, 1361-1380. [CrossRef]

20. Preis, T.; Kenett, D.Y.; Stanley, H.E.; Helbing, D.; Ben-Jacob, E. Quantifying the behavior of stock correlations under market stress. Nat. Sci. Rep. 2012, 2, 1-5. [CrossRef]

21. Münnix, M.C.; Shimada, T.; Schäfer, R.; Leyvraz, F.; Seligman, T.H.; Guhr, T.; Stanley, H.E. Identifying states of a financial market. Nat. Sci. Rep. 2012, 2, 1-6. [CrossRef]

22. Gvozdenovic, I.; Podobnik, B.; Wang, D.; Stanley, H.E. 1/f behavior in cross-correlations between absolute returns in a US market. Phys. A 2012, 391, 2860-2866. [CrossRef]

23. Garas, A.; Argyrakis, P. Correlation study of the Athens stock exchange. Phys. A 2007, 380, 399-410. [CrossRef]

24. Borland, L. Long-range memory and nonextensivity in financial markets. Europhys. News 2005, 36, 228-231. [CrossRef]

25. Sitnov, M.I.; Sharma, A.S.; Papadopoulos, K.; Vassiliadis, D. Modeling substorm dynamics of the magnetosphere: From selforganization and self-organized criticality to non-equilibrium phase transitions. Phys. Rev. E 2001, 65, 016116. [CrossRef]

26. Lui, A.T.Y. Evaluation on the analogy between the dynamic magnetosphere and a force and/or self-organized critical system. Nonlinear Process. Geophys. 2002, 9, 399-407. [CrossRef]

27. Chang, T. An example of resonances, coherent structures and topological phase transitions-the origin of the low frequency broadband spectrum in the auroral zone. Nonlinear Process. Geophys. 2001, 8, 175-179. [CrossRef]

28. Chapman, S.; Watkins, N. Avalanching and self-organised criticality, a paradigm for geomagnetic activity? Space Sci. Rev. 2001, 95, 293-307. [CrossRef]

29. Consolini, G.; Chang, T. Complexity, magnetic field topology, criticality, and metastability in magnetotail dynamics. J. Atmos. Sol. Terrestial Phys. 2002, 64, 541-549.

30. Uritsky, V.; Pudovkin, M.; Steen, A. Geomagnetic substorms as perturbed self-organized critical dynamics of the magnetosphere. J. Atmos. Sol. Terrestial Phys. 2001, 63, 1415-1424. [CrossRef]

31. Balasis, G.; Daglis, I.A.; Kapiris, P.; Mandea, M.; Vassiliadis, D.; Eftaxias, K. From pre-storm activity to magnetic storms: A transition described in terms of fractal dynamics. Ann. Geophys. 2006, 24, 3557-3567. [CrossRef] 
32. Balasis, G.; Daglis, I.A.; Papadimitriou, C.; Kalimeri, M.; Anastasiadis, A.; Eftaxias, K. Dynamical complexity in Dst time series using non-extensive Tsallis entropy. Geophys. Res. Lett. 2008, 35, L14102. [CrossRef]

33. Balasis, G.; Daglis, I.A.; Anastasiadis, A.; Papadimitriou, C.; Mandea, M.; Eftaxias, K. Universality in solar flare, magnetic storm and earthquake dynamics using Tsallis statistical mechanics. Phys. A 2011, 390, 341-346. [CrossRef]

34. Balasis, G.; Papadimitriou, C.; Daglis, I.A.; Anastasiadis, A.; Athanasopoulou, L.; Eftaxias, K. Signatures of discrete scale invariance in Dst time series. Geophys. Res. Lett. 2011, 38, L13103. [CrossRef]

35. Balasis, G.; Donner, R.V.; Potirakis, S.M.; Runge, J.; Papadimitriou, C.; Daglis, I.A.; Eftaxias, K.; Kurths, J. Statistical mechanics and information-theoretic perspectives on complexity in the Earth system. Entropy 2013, 15, 4844-4888. [CrossRef]

36. Daglis, I.A.; Baker, D.N.; Galperin, Y.; Kappenman, J.G.; Lanzerotti, L.J. Technological impacts of space storms: Outstanding issues. EOS Trans. AGU 2001, 82, 585-592. [CrossRef]

37. Kyoto Dst Index Service: Geomagnetic Equatorial Dst Index Home Page. Available online: http://wdc.kugi.kyoto-u.ac.jp/dstdir/ (accessed on 1 March 2021).

38. Carbone, A.; Castelli, G.; Stanley, H.E. Time-dependent Hurst exponent in financial time series. Phys. A 2004, 344, $267-271$. [CrossRef]

39. Tzouras, S.; Anagnostopoulos, C.; McCoy, E. Financial time series modeling using the Hurst exponent. Phys. A 2015, 425, 50-68. [CrossRef]

40. Alvarez-Ramirez, J.; Rodriguez, E.; Alvarez, J. A multiscale entropy approach for market efficiency. Int. Rev. Financ. Anal. 2012, 21, 64-69. [CrossRef]

41. Darbellay, G.A.; Wuertz, D. The entropy as a tool for analyzing statistical dependences in financial time series. Phys. A 2000, 287, 429-439. [CrossRef]

42. Queiros, S.M.D.; Moyano, L.G.; de Souza, J.; Tsallis, C. A nonextensive approach to the dynamics of financial observables. Eur. Phys. J. B 2007, 55, 161-167. [CrossRef]

43. Zhou, R.; Cai, R.; Tong, G. Applications of Entropy in Finance: A Review. Entropy 2013, 15, 4909-4931. [CrossRef]

44. Gabaix, X.; Gopikrishnan, P.; Plerou, V.; Stanly, H.E. A theory of power-law distributions in financial market fluctuations. Nature 2003, 423, 267-270. [CrossRef] [PubMed]

45. Potirakis, S.M.; Minadakis, G.; Nomicos, C.; Eftaxias, K. A multidisciplinary analysis for traces of the last state of earthquake generation in preseismic electromagnetic emissions. Nat. Hazards Earth Syst. Sci. 2011, 11, 2859-2879. [CrossRef]

46. Hatano, T.; Narteau, C.; Shebalin, P. Common dependence on stress for the statistics of granular avalanches and earthquakes. Sci. Rep. 2015, 5, 12280. [CrossRef]

47. Yermolaev, Y.I.; Lodkina, I.G.; Nikolaeva, N.S.; Yermolaev, M.Y. Occurrence rate of extreme magnetic storms. J. Geophys. Res. 2013, 118, 4760-4765. [CrossRef]

48. Saleur, H.; Sammis, C.G.; Sornette, D. Discrete scale invariance, complex fractal dimensions, and log-periodic fluctuations in seismicity. J. Geophys. Res. 1996, 101, 661-677. [CrossRef]

49. Sornette, D. Critical Phenomena in Natural Sciences; Springer: Berlin/Heidelberg, Germany, 2000.

50. Wosnitza, J.H.; Denz, C. Liquidity crisis detection: An application of log-periodic power law structures to default prediction. Phys. A 2013, 392, 3666-3681. [CrossRef]

51. Bhattacharyya, P. Of overlapping Cantor sets and earthquakes: Analysis of the discrete Chakrabarti-Stinchombe model. Phys. A 2005, 348, 199-215. [CrossRef]

52. Bhattacharyya, P.; Chatterjee, A.; Chakrabarti, B.K. A common mode of origin of power laws in models for market and earthquake. Phys. A 2007, 381, 377-382. [CrossRef]

53. Chakrabarti, B.K.; Stinchombe, R.B. Stick-slip statistics for two fractal surfaces: A model for earthquakes. Phys. A 1999, 270, 27-34. [CrossRef]

54. Chakrabarti, B.K.; Chatterjee, A.; Bhattacharyya, P. Two-fractal overlap time series: Earthquakes and market crashes. PRAMANA J. Phys. 2008, 71, 203-210. [CrossRef]

55. Lento, C. Long-Term Dependencies and the Profitability of Technical Analysis. Int. Res. J. Financ. Econ. 2009, $29,126-133$. [CrossRef]

56. Colby, R.W. The Encyclopedia of Technical Market Indicators, 2nd ed.; McGraw-Hill: New York, NY, USA, 2003.

57. Taylor, M.P.; Allen, H. The use of technical analysis in the foreign exchange market. J. Int. Money Financ. 1992, 11, 304-314. [CrossRef]

58. Menkhoff, L. The use of technical analysis by fund managers: International evidence. J. Bank. Financ. 2010, 34, 2573-2586. [CrossRef]

59. Stawicki, S.P. Financial analysis techniques in clinical practice: From 'micro' to 'macro'. OPUS 12 Sci. 2008, 2, 129. [CrossRef]

60. Stawicki, S.P.; Schuster, D.; Liu, J.F.; Kamal, J.; Erdal, S.; Gerlach, A.T.; Whitmill, M.L.; Lindsey, D.E.; Thomas, Y.M.; Murphy, C.; et al. Introducing the glucogram: Description of a noval technique to quantify clinical significance of acute hyperglycemic events. OPUS 12 Sci. 2009, 3, 2-5. [CrossRef]

61. Cowie, B.; Irwin, B. An Evaluation of Trading Bands as Indicators for Network Telescope Datasets. In Proceedings of the SATNAC 2011, East London Convention Centre, East London, UK, 4-7 September 2011; Available online: https://www.researchgate. net/publication/326225071_An_Evaluation_of_Trading_Bands_as_Indicators_for_Network_Telescope_Datasets (accessed on 1 March 2021). 
62. Jung, D.; Lim, J.; Yu, H.; Suh, T. Estimated interval-based checkpointing (EIC) on spot instances in cloud computing. J. Appl. Math. 2014, 2014, 217547. [CrossRef]

63. Ngan, H.Y.T.; Pang, G.K.H. Novel method for patterned fabric inspection using Bollinger bands. Opt. Eng. 2006, 45, 087202. [CrossRef]

64. Thakkar, A.; Kotecha, K. A new Bollinger Band based energy efficient routing for clustered wireless sensor network. Appl. Soft Comput. 2015, 32, 144-153. [CrossRef]

65. Vergura, S. Bollinger Bands Based on Exponential Moving Average for Statistical Monitoring of Multi-Array Photovoltaic Systems. Energies 2020, 13, 3992. [CrossRef]

66. Mendelsohn, L.B. Trend Forecasting with Technical Analysis: Unleashing the Hidden Power of Intermarket Analysis to Beat the Market; Marketplace Books: Ellicott City, MD, USA, 2000.

67. Edwards, R.D.; Magee, J.; Bassetti, W.H.C. Technical Analysis of Stock Trends, 10th ed.; CRC Press: New York, NY, USA, 2012.

68. Gartley, H.M. Profits in the Stock Market; LAMBERT-GANN PUBLISHING CO: Washington, DC, USA, 1935.

69. Murphy, J.J. Technical Analysis of the Financial Markets: A Comprehensive Guide to Trading Methods and Applications; New York Institute of Finance: New York, NY, USA, 1999.

70. Achelis, S.B. Technical Analysis from A to Z, 2nd ed.; McGraw-Hill: New York, NY, USA, 2001.

71. Carr, T.K. Trend Trading for a Living: Learn the Skills and Gain the Confidence to Trade for a Living; McGraw-Hill: New York, NY, USA, 2008.

72. Kirkpatrick, C.D.; Dahlquist, J.R. Technical Analysis: The Complete Resource for Financial Market Technicians, 2nd ed.; FT Press: Upper Saddle River, NJ, USA, 2011.

73. Bollinger, J. Bollinger on Bollinger Bands; McGraw-Hill: New York, NY, USA, 2002.

74. Kiselev, S.A.; Phillips, A.; Gabitov, I. Long scale evolution of a nonlinear stochastic dynamic system for modeling market price bubbles. Phys. Lett. A 2000, 272, 130-142. [CrossRef]

75. McDonald, M. Predict Market Swings with Technical Analysis; John Wiley \& Sons, Inc.: New York, NY, USA, 2002.

76. Liu, W.; Huang, X.; Zheng, W. Black-Scholes' model and Bollinger bands. Phys. A 2006, 371, 565-571. [CrossRef]

77. Xu, S.; Yang, Y. Fractional Black-Scholes Model and Technical Analysis of Stock Price. J. Appl. Math. 2013, 2013, 631795. [CrossRef]

78. Wilder, W.J. New Concepts in Technical Trading Systems; Trend Research: Greensboro, NC, USA, 1978.

79. Kahn, M.N. Technical Analysis Plain and Simple: Charting the Markets in Your Language, 3rd ed.; FT Press: Upper Saddle River, NJ, USA, 2010.

80. Briscoe, S.; Fuller, J. Harriman's Financial Dictionary; Harriman House: Great Britain, UK, 2007.

81. Daglis, I.A.; Kozyra, J.; Kamide, Y.; Vassiliadis, D.; Sharma, A.; Liemohn, M.; Gonzalez, W.; Tsurutani, B.; Lu, G. Intense space storms: Critical issues and open disputes. J. Geophys. Res. 2003, 108. [CrossRef]

82. Daglis, I.A.; Balasis, G.; Ganushkina, N.; Metallinou, F.-A.; Palmroth, M.; Pirjola, R.; Tsagouri, I.A. Investigating dynamic coupling in geospace through the combined use of modeling, simulations and data analysis. Acta Geophys. 2009, 57, 141-157. [CrossRef]

83. Baker, D.N.; Daglis, I.A. Radiation belts and ring current. In Space Weather: Physics and Effects; Bothmer, V., Daglis, I.A., Eds.; Springer: Berlin, Germany, 2007; pp. 173-202.

84. Bulkowski, T.N. Encyclopedia of Chart Patterns, 2nd ed.; John Wiley \& Sons, Inc.: Hoboken, NJ, USA, 2005.

85. Balasis, G.; Mandea, M. Can electromagnetic disturbances related to the recent great earthquakes be detected by satellite magnetometers? Tectonophysics 2007, 431, 173-195. [CrossRef]

86. De Santis, A.; De Franceschi, G.; Spogli, L.; Perrone, L. Geospace perturbations induced by the Earth: The state of the art and future trends. J. Phys. Chem. Earth 2015, 85, 17-33. [CrossRef]

87. De Santis, A.; Balasis, G.; Pavón-Carrasco, F.J.; Cianchini, G.; Mandea, M. Potential earthquake precursory pattern from space: The 2015 Nepal event as seen by magnetic Swarm satellites. Earth Planet. Sci. Lett. 2017, 461, 119-126. [CrossRef]

88. De Santis, A.; Marchetti, D.; Pavón-Carrasco, F.J; Cianchini, G.; Perrone, L.; Abbattista, C.; Alfonsi, L.; Amoruso, L.; Campuzano, S.A.; Carbone, M.; et al. Precursory worldwide signatures of earthquake occurrences on Swarm satellite data. Sci. Rep. 2019, 9, 20287. 